University of Wollongong

Research Online

Faculty of Engineering and Information

Faculty of Engineering and Information

Sciences - Papers: Part A

Sciences

$1-1-2015$

Probing the internal structure of reverse osmosis membranes by positron annihilation spectroscopy: gaining more insight into the transport of water and small solutes

Takahiro Fujioka

University of Wollongong, takahiro@uow.edu.au

Nagayasu Oshima

National Institute of Advanced Industrial Science and Technology (Aist)

Ryoichi Suzuki

National Institute of Advanced Industrial Science and Technology (Aist)

William E. Price

University of Wollongong, wprice@uow.edu.au

Long D. Nghiem

University of Wollongong, longn@uow.edu.au

Follow this and additional works at: https://ro.uow.edu.au/eispapers

Part of the Engineering Commons, and the Science and Technology Studies Commons

Research Online is the open access institutional repository for the University of Wollongong. For further information contact the UOW Library: research-pubs@uow.edu.au 


\title{
Probing the internal structure of reverse osmosis membranes by positron annihilation spectroscopy: gaining more insight into the transport of water and small solutes
}

\author{
Abstract \\ Reverse osmosis (RO) has been employed as a key separation process in many industrial applications. In \\ recent years, the use of positron annihilation spectroscopy (PAS) including positron annihilation lifetime \\ spectroscopy (PALS) and Doppler broadening of annihilation radiation to characterise the internal \\ structure of the skin layer of thin film composite membranes has renewed research interest for further \\ development and optimisation of the RO process. In this paper, we highlight the need for better \\ understanding of the skin layer internal structure. We review relevant PAS techniques that could provide \\ an unprecedented level of insight to our understanding of the internal structure of the active skin layer of \\ RO membranes. PALS data reported in previous studies revealed that commercially available RO \\ membranes have a mean free-volume hole-radius of $0.20-0.29 \mathrm{~nm}$ in the active skin layer. Data \\ corroborated from the literature show a good correlation between the mean free-volume hole-radius of RO \\ membranes and the rejection of boric acid which can be considered as a model small and neutral solute. \\ The data also highlight the need for a comprehensive inter-laboratory study to standardise free-volume \\ hole-radius measurement using PALS. In addition to free-volume hole-radius, free-volume fraction and \\ thickness of the active skin layer appear to be important membrane properties governing neutral solute \\ rejection. A roadmap is suggested to enhance the understanding of the transport of small and neutral \\ solutes in RO. This includes integrating PAS with other techniques (e.g. molecular dynamics simulation) \\ to describe the internal structure of RO membranes. \\ Disciplines \\ Engineering | Science and Technology Studies \\ Publication Details \\ Fujioka, T., Oshima, N., Suzuki, R., Price, W. E. \& Nghiem, L. D. (2015). Probing the internal structure of \\ reverse osmosis membranes by positron annihilation spectroscopy: gaining more insight into the \\ transport of water and small solutes. Journal of Membrane Science, 486 106-118.
}

This journal article is available at Research Online: https://ro.uow.edu.au/eispapers/3599 


\title{
Probing the internal structure of reverse osmosis membranes by positron annihilation spectroscopy: Gaining more insight into the transport of water and small solutes
}

\author{
Revised Manuscript Submitted to \\ Journal of Membrane Science
}

February 2015

Takahiro Fujioka ${ }^{1, *}$, Nagayasu Oshima ${ }^{2}$, Ryoichi Suzuki ${ }^{2}$, William E. Price ${ }^{3}$, and Long D. Nghiem ${ }^{1, *}$

${ }^{1}$ Strategic Water Infrastructure Laboratory, School of Civil Mining and Environmental Engineering, The University of Wollongong, NSW 2522, Australia

${ }^{2}$ National Institute of Advanced Industrial Science and Technology (AIST), Tsukuba, Ibaraki 305-8565, Japan

${ }^{3}$ School of Chemistry, The University of Wollongong, NSW 2522, Australia

\footnotetext{
* Corresponding author: Takahiro Fujioka, Email: takahiro@uow.edu.au, Ph: +61 2 4221 4074; Long Nghiem, Email: longn@uow.edu.au, Ph: +61 242214590.
} 


\section{Abstract}

2 Reverse osmosis (RO) has been employed as a key separation process in many industrial 3 applications. In recent years, the use of positron annihilation spectroscopy (PAS) including 4 positron annihilation lifetime spectroscopy (PALS) and Doppler broadening of annihilation 5 radiation to characterise the internal structure of the skin layer of thin film composite 6 membranes has renewed research interest for further development and optimisation of the RO 7 process. In this article, we highlight the need for better understanding of the skin layer 8 internal structure. We review relevant PAS techniques that could provide an unprecedented 9 level of insight to our understanding of the internal structure of the active skin layer of RO membranes. PALS data reported in previous studies revealed that commercially available RO membranes have a mean free-volume hole-radius of $0.20-0.29 \mathrm{~nm}$ in the active skin layer.

12 Data corroborated from the literature show a good correlation between the mean free-volume 13 hole-radius of RO membranes and the rejection of boric acid which can be considered as a 14 model small and neutral solute. The data also highlight the need for a comprehensive inter15 laboratory study to standardise free-volume hole-radius measurement using PALS. In 16 addition to free-volume hole-radius, free-volume fraction and thickness of the active skin 17 layer appear to be important membrane properties governing neutral solute rejection. A 18 roadmap is suggested to enhance the understanding of the transport of small and neutral 19 solutes in RO. This includes integrating PAS with other techniques (e.g. molecular dynamics 20 simulation) to describe the internal structure of RO membranes.

21 Keywords: boron; free-volume hole; N-nitrosodimethylamine (NDMA); positron 22 annihilation spectroscopy (PAS); and reverse osmosis (RO). 


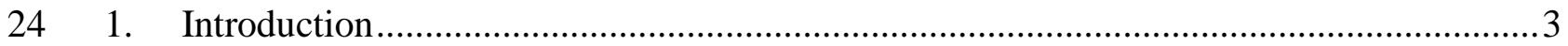

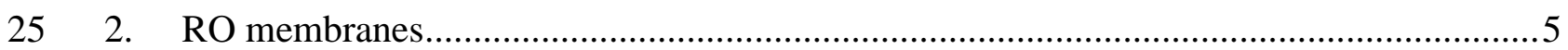

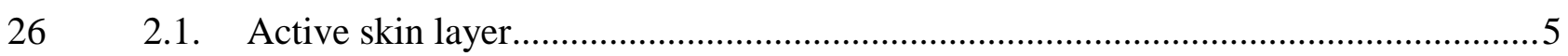

27 2.2. Solute transport through RO membranes ............................................................

28 2.3. Separation performance of commercial RO membranes .............................................9

29 3. Membrane characterisation by PAS........................................................................12

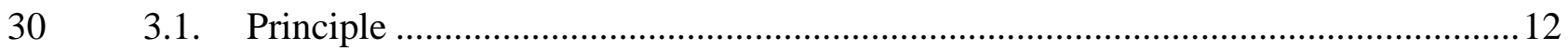

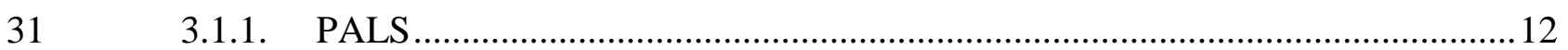

$32 \quad$ 3.1.2. Doppler broadening of annihilation radiation ................................................16

33 3.2. Characterisation of RO membranes ....................................................................17

$34 \quad$ 3.2.1. Free-volume hole-radius of the active skin layer...............................................17

$35 \quad$ 3.2.2. Thickness of the active skin layer................................................................19

36 4. Effect of membrane properties on solute rejection ........................................................20

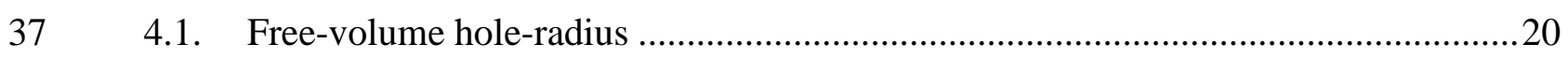

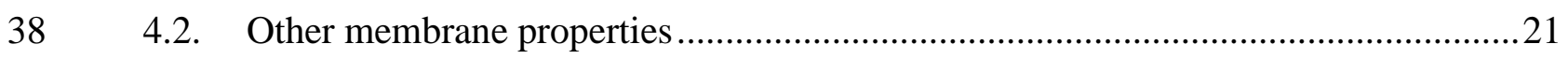

39 5. Future research roadmap ......................................................................................23

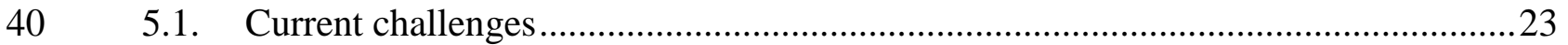

$41 \quad$ 5.2. Complementary techniques ............................................................................26

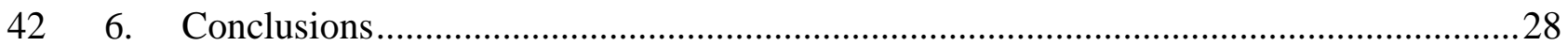

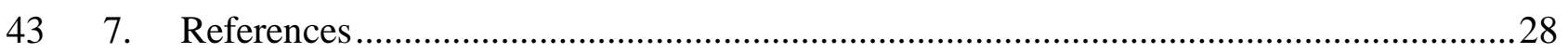




\section{Introduction}

Reverse osmosis (RO) is an important separation process for seawater desalination, potable water reuse, and many other applications. RO membranes can reject a range of inorganic salts and soluble organic substances. RO technology has progressively evolved over the last halfcentury since Loeb and Sourirajan [1] synthesized the first asymmetric cellulose acetate RO membrane capable of removing dissolved salts for desalination purposes in the early 1960s. Another important milestone was the development of the interfacial polymerisation technique for producing thin-film composite (TFC) membranes with high salt rejection and water permeability by Cadotte and Rozelle in the early 1970s [2]. Subsequent development in membrane materials and manufacturing processes has resulted in significant improvements in salt rejection and membrane permeability, making RO efficient and economical for a range of applications [3]. As a notable example, modern seawater reverse osmosis (SWRO) membranes can readily achieve salt rejection of greater than 99.5\% [3]. Other successful applications include brackish water treatment, potable and industrial water reuse, biotechnology, and beverage and dairy production [4-8].

Despite their high salt rejection, the separation efficiency of RO membranes for small and neutral or low molecular weight (MW) molecules is still highly variable. Typical examples of these small and neutral molecules include N-nitrosodimethylamine (NDMA) (MW = 74 $\mathrm{g} / \mathrm{mol}$ ) and boric acid (MW = $62 \mathrm{~g} / \mathrm{mol}$ ). These are contaminants of significant public health or environmental concern. NDMA, a probable human carcinogen [9], is present in raw wastewater and can also be readily formed during chloramination disinfection performed prior to RO filtration. In some cases, low NDMA rejection by RO membranes (e.g., 4-75\%) necessitates subsequent treatment (e.g., advanced oxidation process) or blending and dilution with other clean water to meet its target value (i.e., $10 \mathrm{ng} / \mathrm{L}$ ) [10, 11]. Similarly, seawater desalination plants typically deploy a two pass RO system where the RO permeate from the first pass is treated by the second pass to reduce the boron concentration in the product water to below $0.5 \mathrm{mg} / \mathrm{L}$ [12]. It is noteworthy that commercial SWRO membranes can only achieve a moderate boron rejection (below 90\%) at environmental $\mathrm{pH}$ values (e.g., pH 6-8) where boron exists primarily in the form of boric acid [12]. Difficulties associated with the separation of small compounds present a major challenge to economically operate these water treatment systems. Any improvement on rejection capacity can reduce part or all of the post 
treatment, but requires a comprehensive understanding of solute transport in RO filtration [8, 13].

Solute permeation through RO membranes has been traditionally described by the solutiondiffusion model where RO membranes are assumed to have no visible pores [14]. In the solution-diffusion model, the permeate partitions into the membrane material and diffuses through the RO membrane. Due to difficulties to analyse the internal structure of RO membranes, the solute rejection mechanism has been inferred mostly from the physicochemical properties of the solute $[15,16]$. A recent development in positron annihilation lifetime spectroscopy (PALS) which employs a slow positron beam has allowed for the measurement of the mean size of subnanometre-scale holes (i.e., free-volume holesize) within polymer chains in thin film samples. PALS is an analytical technique using positron annihilation spectroscopy (PAS). It is noteworthy that the free-volume holes cannot be determined by surface characterisation techniques such as transmission electron microscopy (TEM) and scanning electron microscopy (SEM). Other pore size analytical methods such as differential scanning calorimeter and gas adsorption-desorption methods are not suitable or do not have adequate sensitivity to quantify sub-nanometre-scale hole-size [17, 18]. As a result, PAS is the only viable technique to characterise of the internal structure of RO membranes. The number of PALS studies for RO membrane characterisation has increased significantly over the last few years [19-25]. However, contribution of free-volume holes to solute permeation has not yet been fully understood. It is also noteworthy that other properties of the free-volume hole including shape and free-volume fraction cannot be measured by PALS. Thus, further development of supplementary tools (such as molecular dynamics simulation [13]) to characterise these properties (that may influence the diffusion of neutral solutes through TFC RO membranes) is also crucial to better understand their transport behaviour.

Given the need to clarify the potential of PAS/PALS for elucidating solute separation mechanisms, this review aims to provide a comprehensive understanding of solute-membrane interactions in RO filtration, particularly focusing on free-volume hole-size analysed by PALS. The specific objectives are to evaluate the relationship between free-volume hole-size and the rejection of small and neutral solutes; and discuss the potential of the current PAS techniques for characterising RO membranes. 


\section{RO membranes}

108

109

110

111

112

113

\subsection{Active skin layer}

Most commercial RO membranes are polyamide or polyamide derivative thin-film composites. Indeed, since the development of interfacial polymerisation techniques for membrane production in the 1970s $[2,26]$, TFC RO membranes have become the industry standard. A typical TFC membrane comprises an active polyamide (or polyamide derivative) skin layer on top of a polysulfone microporous supporting layer, which is further supported by a polyether non-woven fabric backing layer (Figure 1). The thicknesses of these three layers are approximately $0.05-0.2,50$, and $100 \mu \mathrm{m}$, respectively [27-30]. The active skin exclusively determines the water permeability and solute separation efficiency of the membrane. The polyether backing and polysulfone support layers do not contribute to the separation process and their role is solely to provide mechanical support to the active skin layer.

The active skin layer is formed by interfacial polymerisation where an aqueous solution containing a polyfunctional amine placed on the support layer reacts with another solvent solution containing polyfunctional acid chloride at their interface [31]. The polymerisation is usually incomplete and there can be a number of unreacted amine and carboxylic functional groups [32]. Interfacial polymerisation conditions (e.g., monomer concentration, solvent properties, reaction time and temperature) influence the characteristics of the active skin layer and determine the separation performance and water permeability of the RO membrane [3335]. It is widely accepted that free-volume holes are present between cross-linked polymer chains of the active skin layer into which water molecules and small solutes can partition (Figure 1) [23, 36, 37]. 


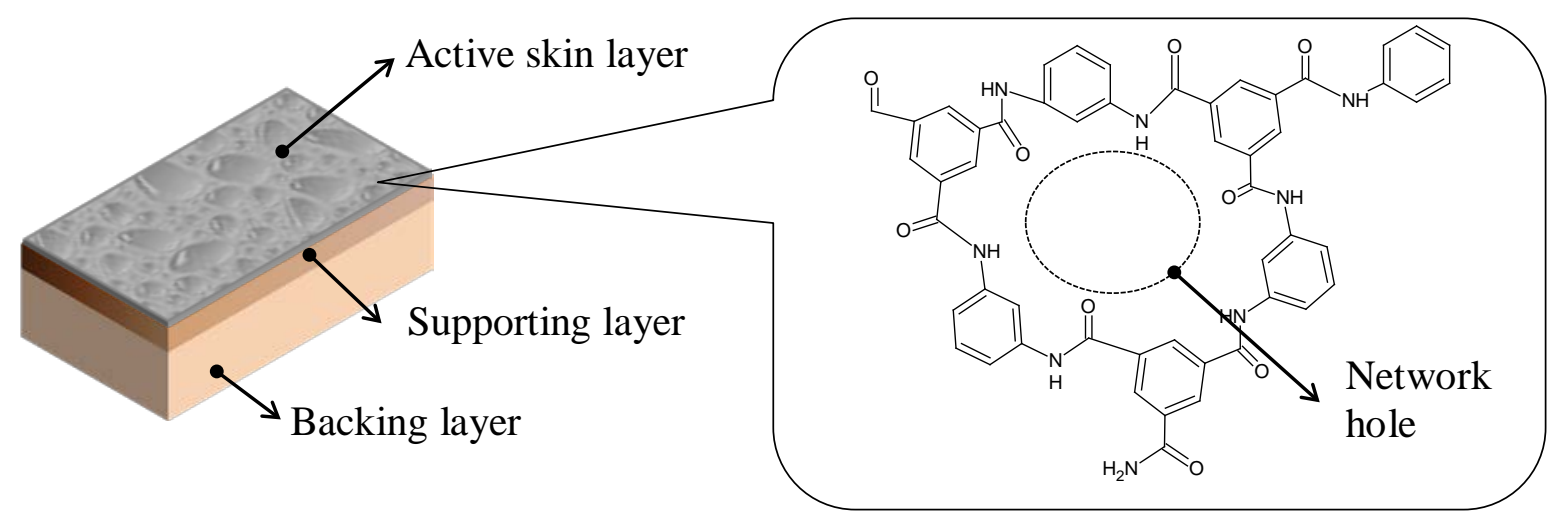

130

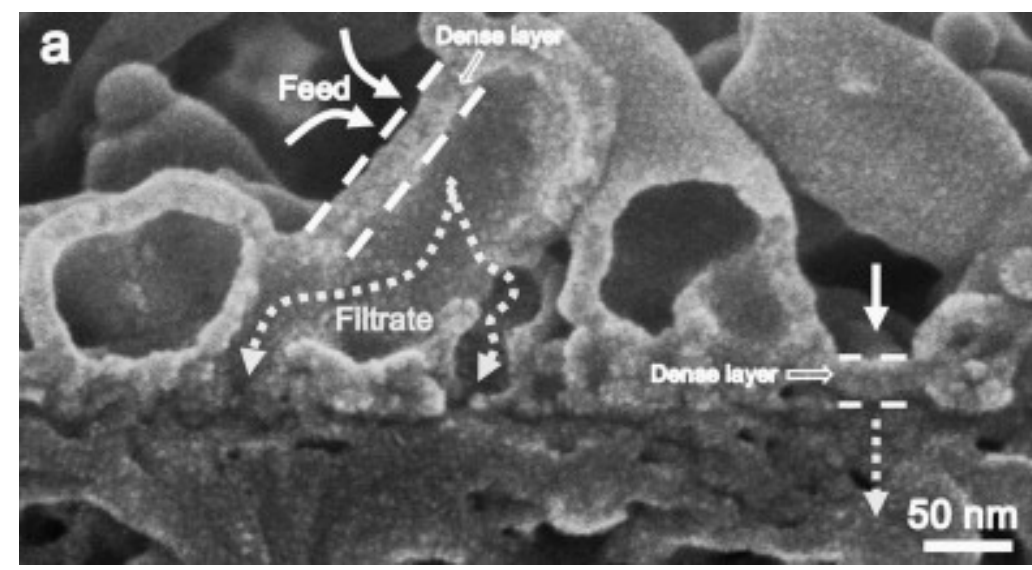

143 Figure 2: Scanning electron microscopy cross-section image of ESPA2 membrane. (a)

144 Cutting lines show the position of a dense layer, with an average thickness of ca. $20 \mathrm{~nm}$.

145 Dotted lines show passages for filtrate to go through under pressure; (b) Fractured ridge 146 structure, a cavity can be seen on the root (Reproduced with permission from Ref. [38]. 147 Copyright 2014 Elsevier Science). 


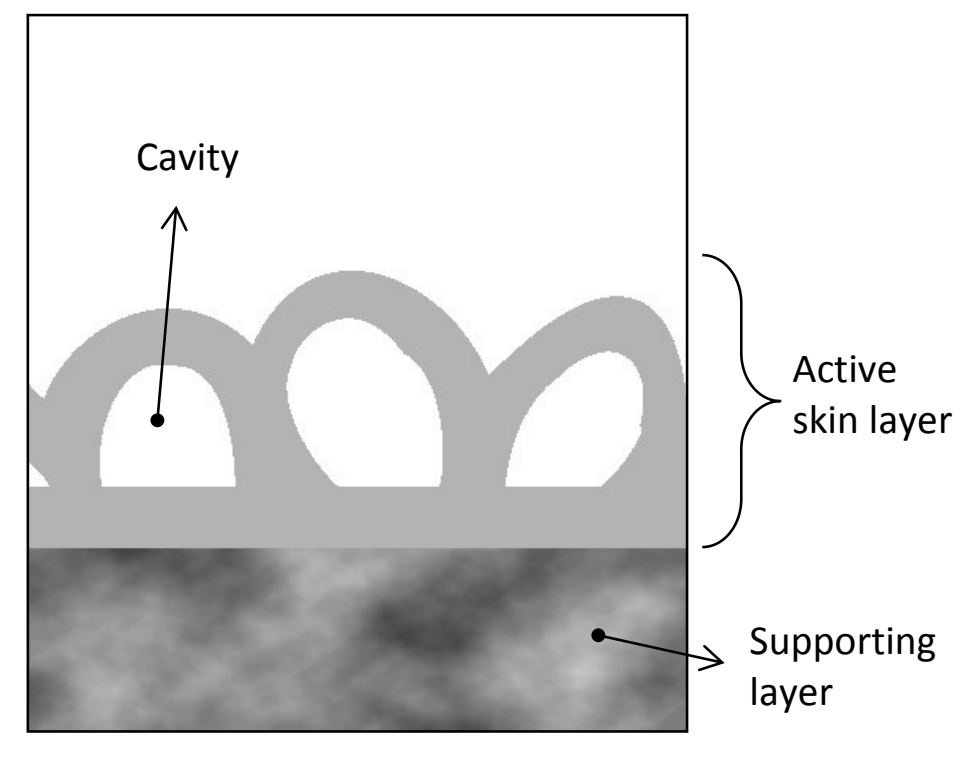

149 Figure 3: Schematic cross-sectional image of the active skin layer of an RO membrane.

\subsection{Solute transport through RO membranes}

151 Solute transport across an RO membrane is generally described by the irreversible 152 thermodynamics, pore-flow, or solution-diffusion models [14, 41-43]. The irreversible

153 thermodynamic model $[42,43]$ has been widely used to describe and quantify the transport of 154 solvent and solutes through RO membranes using a set of phenomenological equations.

155 Nevertheless, it provides no insight into membrane properties and solute transport 156 mechanisms. Thus, the model is not suited to describe the transport of solvent and solutes 157 based on the membrane free-volume hole-radius. The pore-flow model is essentially based on 158 a fixed free-volume hole network within the membrane matrix [41, 44]. This model describes 159 the transport of solutes through these holes by pressure-driven convective flow, which can 160 separate solutes under a size exclusion mechanism. Within this model, free-volume hole-size 161 is an important parameter governing the diffusion and convection of solutes through the 162 active skin layer.

163 In contrast to the pore-flow model where permanent free-volume holes exist in the active skin 164 layer, the solution-diffusion model is based on the concept of a "non-porous" membrane. Salt 165 transport through RO membranes in most studies is described with diffusion - the basis of the 166 solution-diffusion model. In this model, the separation of solutes through a membrane occurs 167 due to the difference in solubility and mobility of solutes that are dissolved in the membrane 168 matrix $[14,45,46]$. The driving force producing the separation is a concentration gradient 
across the membrane. Solutes diffuse the membrane through the appearing and disappearing

170 free-volume holes between polymer chains having the thermal motion [47]. Salt and water

171 transport in RO is facilitated by molecular diffusion involves two components - water

172 (component $i$ ) and salt (component $j$ ). The water flux $\left(J_{i}\right)$ is described by the simple equation

$173 \quad J_{i}=A(\Delta P-\Delta \pi)$

174 where $\Delta \mathrm{P}$ and $\Delta \pi$, respectively, are the pressure difference and osmotic pressure difference

175 across the membrane, $A$ is the water permeability constant and

$176 \quad A=\frac{D_{i} K_{i} c_{i 0} V_{i}}{l R T}$

177 where $D_{i}$ is the water diffusion coefficient, $K_{i}$ is the water sorption coefficient, $c_{i 0}$ is the

178 concentration of water in the feed, $V_{i}$ is the molar volume of water, $l$ is the membrane

179 thickness, $R$ is the gas constant, and $T$ is the water temperature. Similarly, the salt flux $\left(J_{j}\right)$

180 across the RO membrane can be written as

$181 J_{j}=B \Delta c_{j}$

182 where $\Delta c_{j}$ is the salt concentration difference across the membrane, $B$ is the salt permeability

183 constant and

$184 \quad B=\frac{D_{j} K_{j}}{l}$

185 where $D_{j}$ is the salt diffusion coefficient and $K_{j}$ is the salt sorption coefficient. Unlike water

186 flux, salt flux is independent of the difference in pressure and osmotic pressure across the

187 membrane. A more detailed description of the solution-diffusion model can be found 188 elsewhere [14, 47, 48]. The ability of solute separation performance of RO membranes is 189 typically expressed with the term - apparent solute rejection $\left(R_{s}\right)$

190

$$
R_{s}=\left(1-\frac{C_{s l}}{C_{s 0}}\right)
$$


193 Filtration operating conditions can be important parameters when comparing the rejection of a 194 given solute among different TFC membranes. These conditions include permeate (or water) 195 flux which represents permeate flow rate per unit area (e.g., $\left.\mathrm{L} / \mathrm{m}^{2} \mathrm{~h}\right)$. Permeate flux increases 196 with applied feed pressure but solute flux remains almost unchanged [14], leading to 197 increased dilution of solute in the permeate stream (Figure 4). As a result, solute rejection can 198 vary depending on permeate flux. Thus, separation performance among different RO 199 membranes needs to be evaluated under controlled filtration conditions.

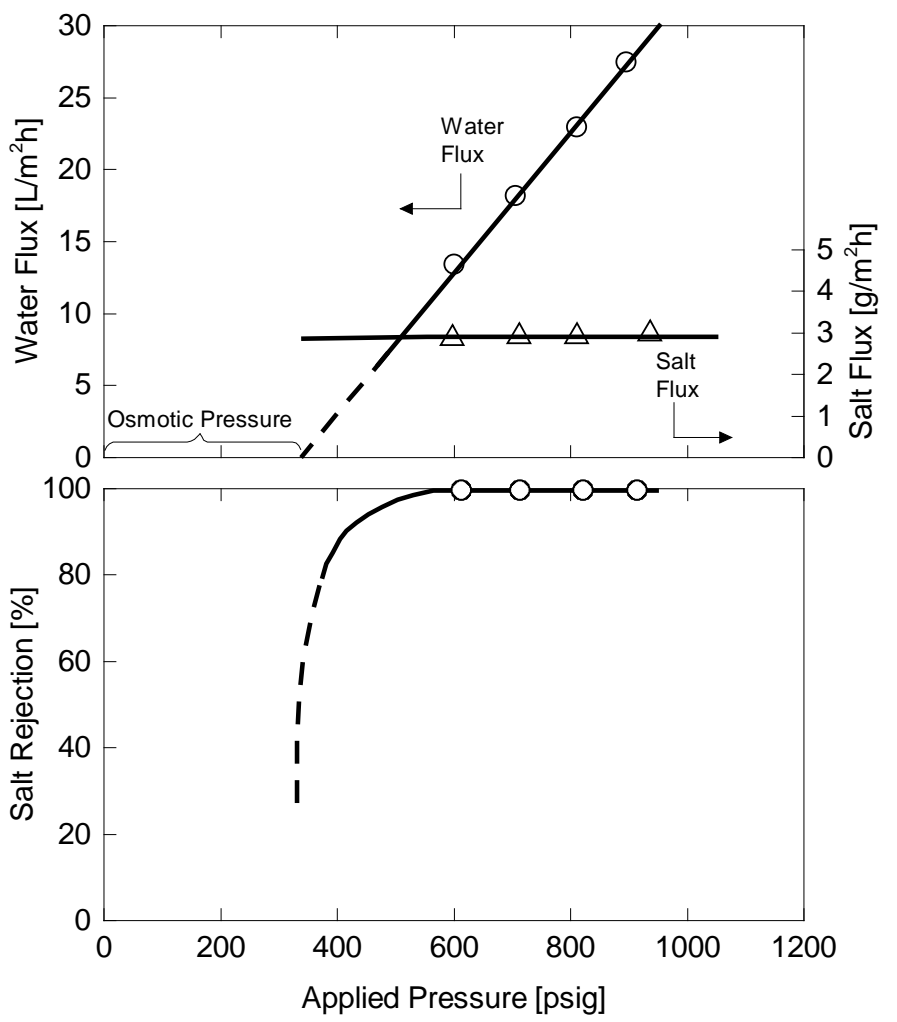

Figure 4: Flux and rejection data for a model seawater solution (3.5\% sodium chloride) in a good quality reverse osmosis membrane as a function of pressure (Reproduced with permission from Ref. [14]. Copyright 1995 Elsevier Science).

\subsection{Separation performance of commercial RO membranes}

205 The rejection of sodium chloride $(\mathrm{NaCl})$ is usually used to describe the separation 206 performance of RO membranes. Typically TFC-based SWRO membranes can readily achieve 
more than 99.5\% $\mathrm{NaCl}$ rejection at a high salt concentration (e.g., 30,000 mg/L) and pressure 208 (e.g., $5.5 \mathrm{MPa}$ ) [3]. Low pressure reverse osmosis (LPRO) membranes, designed for low 209 salinity water applications (e.g., pre-treatment of ultrapure water, boiler water, brackish water 210 and wastewater recycling), attain moderate to high salt rejection (e.g., 99.3-99.7\%) (Table 1). 211 LPRO membranes employed in water recycling applications are expected to remove some 212 trace organic chemicals (TrOCs) in addition to salts [49, 50]. In contrast to RO membranes 213 which reject most monovalent ions, nanofiltration (NF) membranes have a low $\mathrm{NaCl}$ rejection 214 but can achieve sufficient removal of multivalent ions such as magnesium, calcium and 215 phosphate. Although sodium ion is a very small solute (molecular mass $=23 \mathrm{~g} / \mathrm{mol}$ ), in an 216 aqueous solution it exists in a hydrated form which is several times larger than the naked ion. 217 Hydrated sodium ions can be larger in diameter than the free-volume hole of the RO active 218 skin layer [27]. As a result, most hydrated ions will be rejected by RO membranes, resulting 219 in a high salt rejection. Most if not all charged compounds also exhibit high rejection by RO 220 membranes by electrostatic repulsion and size exclusion mechanisms [51].

221 Table 1: Separation properties of commercial NF/RO membranes.

\begin{tabular}{|c|c|c|c|c|c|c|c|}
\hline \multirow[t]{2}{*}{ Type } & \multirow[t]{2}{*}{ Membrane } & \multirow[t]{2}{*}{ Manufacturer } & \multicolumn{3}{|c|}{ Manufacturer's data } & \multirow{2}{*}{$\begin{array}{l}\text { Boron } \\
\text { rejection }^{\text {a }} \\
{[\%]}\end{array}$} & \multirow{2}{*}{$\begin{array}{l}\text { NDMA } \\
\text { rejection }^{\mathrm{a}} \\
{[\%]}\end{array}$} \\
\hline & & & $\begin{array}{l}\text { Pressure } \\
{[\mathrm{MPa}]}\end{array}$ & $\begin{array}{l}\mathrm{NaCl} \\
\text { rejection } \\
{[\%]}\end{array}$ & $\begin{array}{l}\mathrm{MgSO}_{4} \\
\text { rejection } \\
{[\%]}\end{array}$ & & \\
\hline SWRO & SWC5 & Hydranautics/Nitto & 5.50 & 99.8 & - & $81^{b}$ & $78^{b}$ \\
\hline \multirow{7}{*}{ LPRO } & ESPAB & Hydranautics/Nitto & 1.05 & 99.3 & - & $59^{b}$ & $71^{b}$ \\
\hline & ESPA2 & Hydranautics/Nitto & 1.05 & 99.6 & - & $36^{\mathrm{b}}$ & $34^{\mathrm{b}}$ \\
\hline & ESPA1 & Hydranautics/Nitto & 1.05 & 99.3 & - & $12^{\mathrm{c}}$ & $23^{\mathrm{c}}$ \\
\hline & LFC3 & Hydranautics/Nitto & 1.05 & 99.7 & - & n.a. & $38^{\mathrm{d}}$ \\
\hline & $70 \mathrm{LW}$ & Toray & 1.55 & 99.7 & - & n.a. & $52^{\mathrm{d}}$ \\
\hline & TFC-HR & KMS & 1.55 & 99.6 & - & $58^{\mathrm{c}}$ & $50^{\mathrm{c}}$ \\
\hline & BW30 & Dow/Filmtec & 1.55 & 99.5 & - & $39^{c}$ & $48^{\mathrm{c}}$ \\
\hline \multirow{2}{*}{ NF } & NF90 & Dow/Filmtec & 0.48 & $85-95$ & $>97$ & n.a. & $8^{\mathrm{d}}$ \\
\hline & NF270 & Dow/Filmtec & 0.48 & - & 97 & n.a. & $4^{e}$ \\
\hline
\end{tabular}

$222{ }^{a}$ Determined using a laboratory-scale RO system with overall permeate flux $=20 \mathrm{~L} / \mathrm{m}^{2} \mathrm{~h}$; feed 223 solution contains $20 \mathrm{mM} \mathrm{NaCl}, 1 \mathrm{mM} \mathrm{NaHCO}_{3}$, and $1 \mathrm{mM} \mathrm{CaCl}_{2}$; cross flow velocity 40.2

$224 \mathrm{~cm} / \mathrm{s}$; feed temperature $=20.0 \pm 0.1^{\circ} \mathrm{C}$; feed $\mathrm{pH} 8.0 \pm 0.1$.

$225{ }^{b}$ Ref. [20]

$226{ }^{\mathrm{c}}$ Ref. [52]

$227{ }^{\mathrm{d}}$ Ref. [53]

$228{ }^{\mathrm{e}}$ Unpublished

229 n.a.: not available 
In contrast to charged solutes, the rejection of neutral solutes by RO membranes can be low and highly variable. Typical examples include boron and NDMA that are small and present in natural water in an uncharged form [52, 53] (Table 2). For example, the rejection of boric acid $(\mathrm{MW}=62 \mathrm{~g} / \mathrm{mol})$ and NDMA (MW = $74 \mathrm{~g} / \mathrm{mol}$ ) by RO membranes in the literature is 12 $81 \%$ and $23-78 \%$, respectively (Table 1). It is noteworthy that the specifications of commercial RO membranes do not always include information regarding the removal of small and neutral solutes of significant health and ecological concern (e.g., NDMA and boron). Unlike charged solutes, these small and neutral solutes are primarily rejected through size exclusion whereby solutes larger than the free-volume holes of membrane are effectively rejected while allowing smaller ones to permeate through [51, 54]. In fact, the rejection of neutral solutes by RO membranes generally increase with molecular size (e.g., molecular volume) [20, 22].

242 Table 2: Properties of boric acid and NDMA.

\begin{tabular}{lll}
\hline Membrane type & Boric Acid & NDMA \\
\hline Structure & & \\
& &
\end{tabular}

247 A recent study by Fujioka et al., [55] revealed that the rejection of neutral solutes by TFC 248 membranes was better correlated with the solute minimum projection area (MPA, the 249 minimum 2D dimension of the solute) than either the molecular weight or molecular volume 250 (Figure 5). Fujioka et al., [55] suggested that the size interaction between solute and 251 membrane is important in determining neutral solute rejection. Uncharged compounds such as 252 boric acid and NDMA are very hydrophilic (Table 2) but most commercial RO membranes 253 are classified as hydrophobic. Thus, hydrophobic interactions (e.g., adsorption) between these 
types of solutes and membranes hardly occur [56]. As a result, free-volume hole-size is expected to be the most important factor governing the rejection of a given neutral solute.

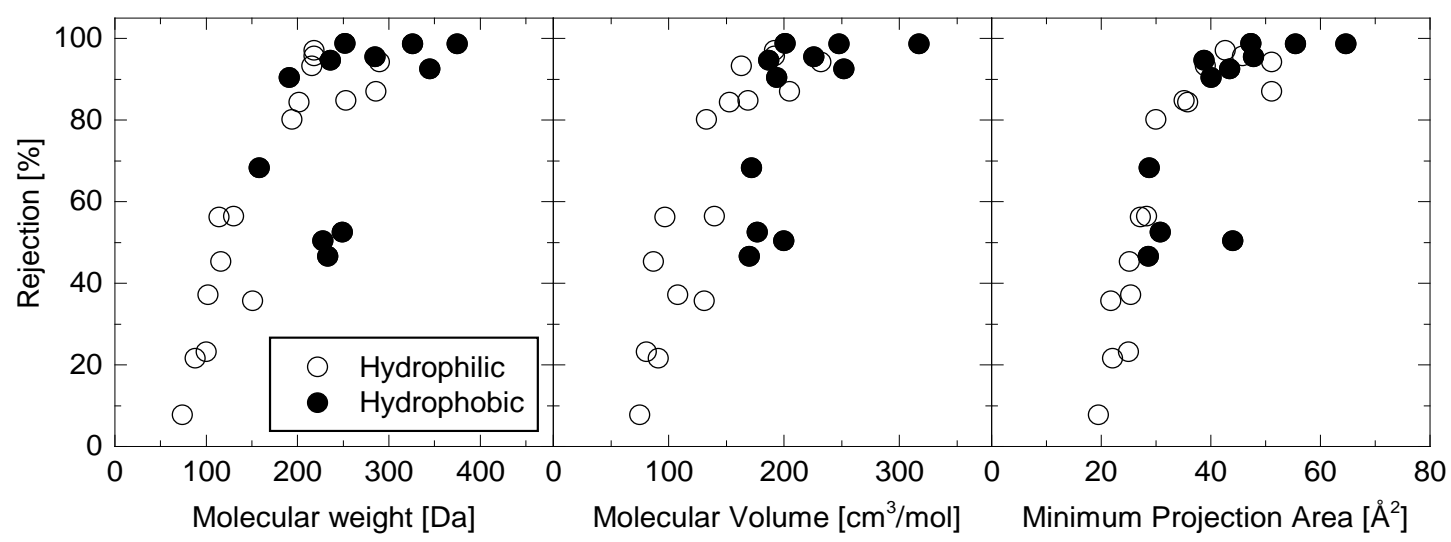

256

257

258

259

260

261

262

263

264

265

266

267

268

269

270

271

272

273

274

275

Figure 5: Rejection of 28 neutral TrOCs by the NF90 membrane as a function of their molecular weight, molecular volume and minimum projection area $(20 \mathrm{mM} \mathrm{NaCl}, 1 \mathrm{mM}$ $\mathrm{NaHCO}_{3}, 1 \mathrm{mM} \mathrm{CaCl}$, permeate flux $20 \mathrm{~L} / \mathrm{m}^{2} \mathrm{~h}$, feed pH $8.0 \pm 0.1$, feed temperature $20.0 \pm$ $0.1^{\circ} \mathrm{C}$ ) (Reproduced with permission from Ref. [55]. Copyright 2014 Elsevier Science).

\section{Membrane characterisation by PAS}

\subsection{Principle}

The free-volume hole-structure of thin films including the active skin layer of RO membranes can be evaluated using PAS. The most commonly used analytical methods in PAS are: (a) PALS in which the lifetime spectrum of positrons and/or positroniums is measured; and (b) Doppler broadening of annihilation radiation (DBAR) in which the energy spectrum of the annihilation $\gamma$-rays is measured. PALS can be used to evaluate the free-volume hole-radius of the membrane active skin layer. On the other hand, DBAR can be used to examine electron momentum distributions and provides information on the positron (positronium) annihilation process and/or analysis of the chemical composition at the annihilation site within the membrane active skin layer.

\subsubsection{PALS}

PALS is currently the only technique capable of determining the free-volume hole-radius within the active skin layer of an RO membrane [17, 22]. The analysis is performed by injecting positrons into the membrane sample where positrons annihilate with electrons 
resulting in the emission of annihilation $\gamma$-rays. Some of the positrons injected into insulating materials (e.g., polymers) combine with an electron and then form a hydrogen-like bound state of an electron - positronium ion (Ps). Ps can exist in two different states. One is a spinantiparallel state, para-Ps (p-Ps), and the other is spin-parallel state, ortho-Ps (o-Ps). In vacuum, $p$-Ps annihilate into $2-\gamma$ rays (2- $\gamma$ decay) with an intrinsic lifetime of 125 ps while $o$ Ps annihilate into 3- $\gamma$ rays (3- $\gamma$ decay) with an intrinsic lifetime of $142 \mathrm{~ns}$. When $o-\mathrm{Ps}$ is generated in an insulating sample, they are trapped in free-volume holes and subsequently self-annihilate. Within the free-volume hole $o$-Ps can also annihilate with surface wall electrons by 2- $\gamma$ decay (pick-off annihilation) with a lifetime shorter than 142 ns. With decreasing free-volume hole-size the probability of pick-off annihilation increases, and $o$-Ps life-time becomes shorter. Although the $o$-Ps annihilates with a lifetime much shorter than $142 \mathrm{~ns}$ in a polymer sample, it still survives far longer than the $p$-Ps (i.e., $125 \mathrm{ps)}$ and free positrons (i.e., $\sim 0.4$ ns) which enables the lifetime of $o$-Ps decaying in a free-volume hole to be measured by PALS. The lifetime of $o$-Ps $\left(\tau_{o \text {-Ps }}\right)$ in pick-off annihilation can be expressed using the Tao-Eldrup model $[57,58]$ :

$$
\tau_{o-P s}=0.5\left[1-\frac{r}{r+0.166}+\frac{1}{2 \pi} \sin \left(\frac{2 \pi r}{r+0.166}\right)\right]^{-1}
$$

where $r(\leq 1 \mathrm{~nm})$ is the radius of the free-volume hole approximated as a spherical shape.

There are two major methods for measuring positron lifetime. One is called the "fast positron method", using fast positrons obtained by $\beta^{+}$decay of ${ }^{22} \mathrm{Na}$ radioactive isotopes (RIs) [19, 23] (Figure 6a). The other is called the "slow positron method", in which slow positrons generated by moderation of fast positrons are used (Figure 6b).

In the fast positron method, ${ }^{22} \mathrm{Na}$ sealed by a Kapton thin film is used as a positron source. The positron beam is typically a few millimetres in diameter. This positron source is sandwiched by two pieces of sample of several millimetres in diameter and about $1 \mathrm{~mm}$ apart (Figure 6a). Positrons generated from the positron source have up to $540 \mathrm{keV}$ in energy and can penetrate up to $0.1 \mathrm{~mm}$ in depth into the sample. Thus, the information obtained by this method is the average value of the bulk sample. Positron and $1.27 \mathrm{MeV} \gamma$-ray are both emitted from ${ }^{22} \mathrm{Na}$ almost simultaneously. Positron lifetime is defined as the time difference between the detection timing of the $1.27 \mathrm{MeV} \gamma$-ray (i.e., start timing signal) and the detection timing 
of the annihilation $\gamma$-ray (i.e., stop timing signal). It is noteworthy that Ps is not formed in the 306 Kapton thin film and hence $o$-Ps lifetime measured by the first positron method is the 307 information solely originating from the sample.
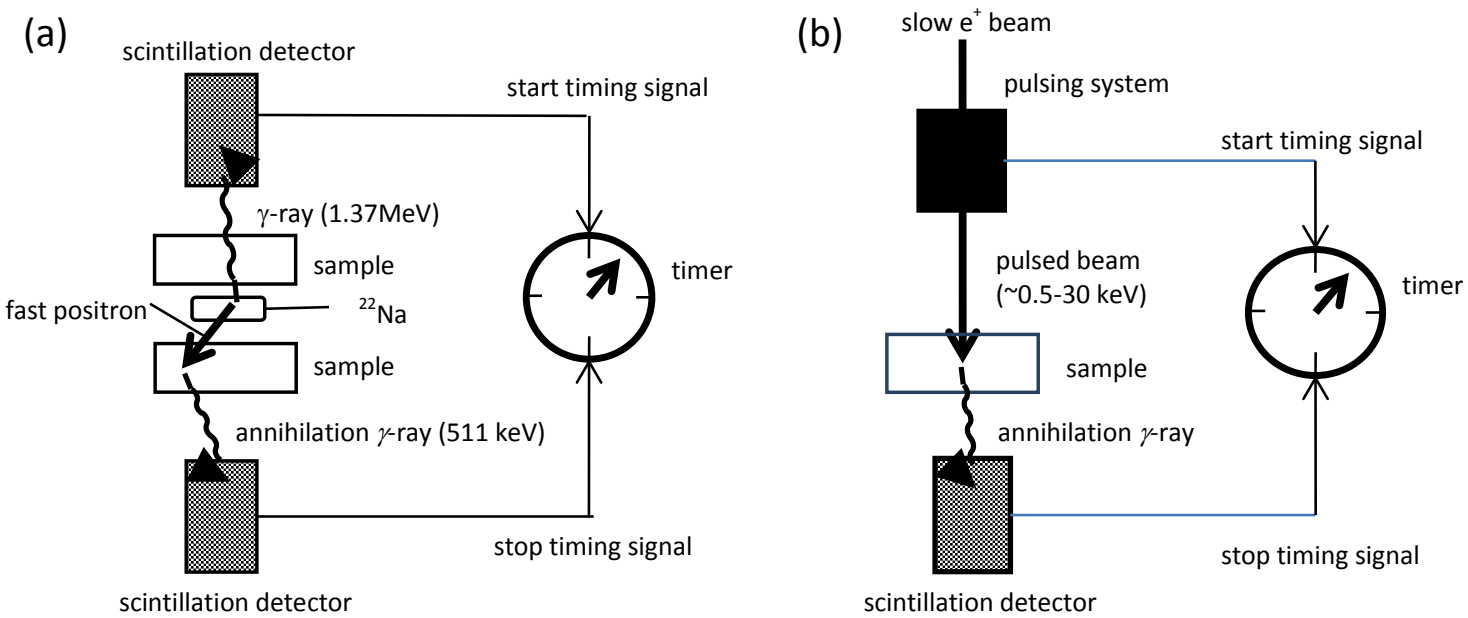

308

309 Figure 6: Schematic diagram of PALS measurement techniques (a) fast positron method and 310 (b) slow positron method.

311 In contrast to the fast positron method, the slow positron method uses a monoenergetic 312 positron beam with an energy spread of $\sim 10 \mathrm{eV}$. Slow positrons are generated by moderation 313 of fast positrons created by intense RI sources or electron accelerators. These slow positrons 314 can be guided as a beam through the vacuum-duct (beamline) to the measurement chamber 315 and injected into a sample. By adjusting the injection energy $\left(E_{i n}\right)$ typically from $0.5 \mathrm{keV}$ to $31630 \mathrm{keV}$ of a slow positron beam, the positron implantation depth can be controlled allowing 317 depth analysis from several nm to several um of free-volume hole-radius in the material. The 318 mean positron implantation depth $z_{m}$ is estimated by the semi-empirical formula $z_{m}$ [nm] $\approx$ $31940 E_{i n}{ }^{1.6}[\mathrm{keV}] / \rho\left[\mathrm{g} / \mathrm{cm}^{3}\right]$, where $\rho$ is density of sample [59]. For example, a positron incident 320 energy of $1.0 \mathrm{keV}$ corresponds to a mean implantation depth of about $40 \mathrm{~nm}$ for polyamide 321 membrane samples. The stopping profile $P\left(z, E_{i n}\right)$ of positrons in materials is approximately 322 given by the following semi-empirical equations:

$$
P\left(z, E_{\text {in }}\right)=\frac{2 z}{z_{0}{ }^{2}} \exp \left[-\left(\frac{z}{z_{0}}\right)^{2}\right]
$$

$$
z_{0}=\frac{z_{m}}{\Gamma(3 / 2)}
$$


325 where $z$ is the depth (in nm), $\Gamma$ is the gamma function, and $\int_{0}^{\infty} P\left(z, E_{\text {in }}\right) d z=1 . P\left(z, E_{\text {in }}\right)$ is 326 defined as the stopping profile of positrons before thermal diffusion and the actual 327 annihilation depth profile of positron and o-Ps can be broadened due to their diffusions 328 occurring prior to annihilation. However, $P\left(z, E_{i n}\right)$ can be used as actual annihilation depth 329 profile of positron/o-Ps provided that the diffusion length of positron/o-Ps is adequately small 330 compared to the mean implantation depth $z_{m}$. It is important to note that typical o-Ps diffusion 331 length is within a few nm [60]. With this approximation, the measured value of positron 332 annihilation parameters $Q$ can be given by $Q=\int_{0}^{\infty} P\left(z, E_{i n}\right) \times Q(z) d z$. When positrons are 333 injected into a sample with distinct multi-layers, $Q$ is given by using the stopping probability $334 \eta_{i}$ and intrinsic positron annihilation parameters $Q_{i}$ in the layer number $i$ (e.g., $i=1$ is the top 335 layer and $i=2$ is the second layer located under the top layer) as follows:

$\eta_{i}\left(E_{\text {in }}\right)=\int_{x_{i}}^{x_{i+1}} P_{i}\left(z, E_{i n}\right) d z$

$Q=\sum_{i} \eta_{i}\left(E_{i n}\right) \times Q_{i}$

338 where $x_{i}$ is the depth from the surface to the interface between the layer of $i$ - 1 and the layer $i$.

339 Calculated $P\left(z, E_{\text {in }}\right)$ for $E_{\text {in }}=1.0,2.0$ and $3.0 \mathrm{keV}$ are illustrated in Figure 7. The distribution 340 profile of positron implantation depth becomes more widespread as $E_{\text {in }}$ increases (Figure 7). 341 In general samples have to be mounted under vacuum conditions during measurement in the 342 slow positron method.

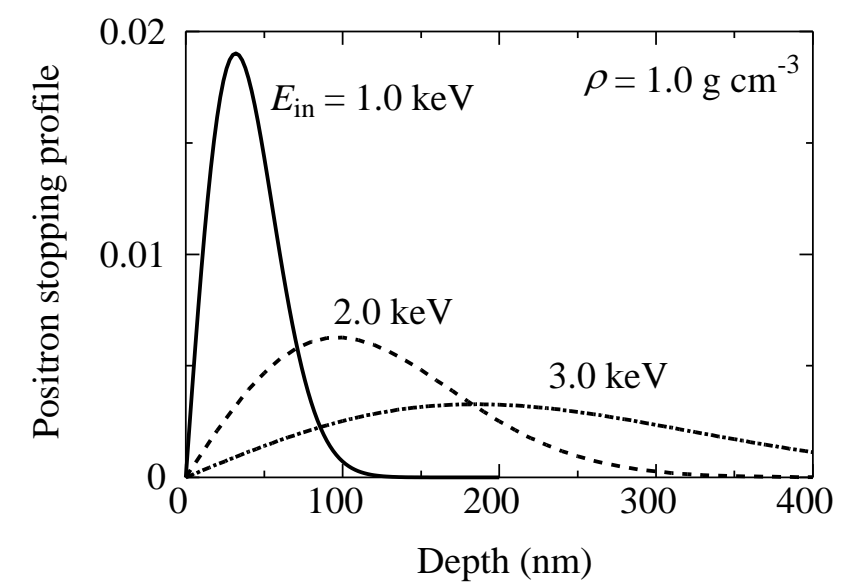

344 Figure 7: Typical distribution of positron implantation depth in a polyamide membrane 345 sample with a positron incident energy of 1.0, 2.0 and $3.0 \mathrm{keV}$ (Unpublished). 
346 A typical example of a positron lifetime measurement system using a slow positron beam is 347 described in Figure 6b. The lifetime of positron is measured as the time difference between 348 the pulsing trigger from the beam pulsing system (start timing signal) and the detection timing 349 of the annihilation $\gamma$-ray detected by a scintillation detector (stop timing signal) [61]. The 350 measurement is carried out under vacuum (e.g., $10^{-5} \mathrm{~Pa}$ ). Approximately $2-3 \times 10^{6}$ events of 351 positron annihilation are collected to obtain one positron lifetime spectrum. A typical lifetime 352 spectrum obtained using the slow positron method is shown in Figure 8. In general, lifetime 353 spectrum is analysed with a few parameters in an exponential decaying curve $354 \sum_{i} \frac{I_{i}}{\tau_{i}} \exp \left(-\frac{t}{\tau_{i}}\right)$ where $\tau_{i}$ and $I_{i}$ are the lifetime and relative intensity $\left(\sum_{i} I_{i}=1\right)$ of 355 component $i$, respectively. In most cases, components longer than 1 ns can be attributed to the 356 $o$-Ps lifetime. The positron lifetime spectra can be analysed by deriving $\tau_{l}$ and $I_{i}$ using a nonlinear least-squares fitting program in which the time resolution function of the measurement system is taken into account. Further details of PALS are described elsewhere $[17,59]$.

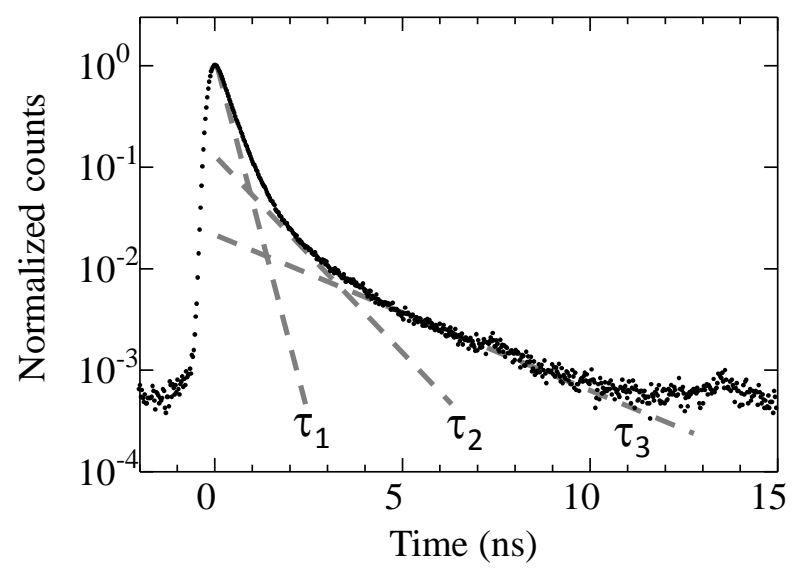

359

360

361

362

363

364

365

366 367

Figure 8: Example of lifetime spectrum obtained using the slow positron method (Unpublished).

\subsubsection{Doppler broadening of annihilation radiation}

Unlike PALS from which information associated with the size of free-volume holes is obtained by measuring positron/Ps lifetimes, DBAR can yield other/additional information related to the structure of the sample by measuring the annihilation $\gamma$-ray energy spectrum. For example, the shape of the energy spectrum around the $2-\gamma$ annihilation peak (511 keV) is affected by the chemical composition and electron state at the site of the positron annihilation 
within the sample. Therefore, DBAR can often detect changes in the nano-structure of samples even if their free-volume hole-sizes are the same.

370

371

372

$2-\gamma$ decay probability of $o$-Ps due to the pick-off annihilation increases with decreasing freevolume hole-size and consequently 3- $\gamma$ decay probability decreases. Therefore, we can obtain information on free-volume hole-size if we measure ratio of $2-\gamma$ decay to $3-\gamma$ decay. When $o-$ Ps is annihilated with 2- $\gamma$ decay, $\gamma$-ray energy is detected at $511 \mathrm{keV}$. On the other hand, $o$-Ps annihilated with 3- $\gamma$ decay is detected at a lower energy with a broader distribution (e.g., 365$495 \mathrm{keV}$ ) [22]. The 3- $\gamma / 2-\gamma$ annihilation ratio is evaluated by analysis of the energy spectrum.

The $\gamma$-ray energy spectra can be collected by using a Germanium detector [62, 63]. With the slow positon method, the top surface of the sample can be analysed by DBAR. DBAR is useful to qualitatively evaluate changes in chemical composition, electron bonding state, and free-volume hole-size. Although this review focuses particularly on PALS which is directly linked to the measurement of free-volume hole-radius, it is noteworthy that DBAR can be used in conjunction with PALS to analyse the inner structure of free-volume holes.

\subsection{Characterisation of $R O$ membranes}

\subsubsection{Free-volume hole-radius of the active skin layer}

Over the past decade PALS techniques have been progressively applied to the analysis of the internal structure of NF/RO membranes [63-71]. The free-volume hole-radius of commercial NF/RO membranes reported in literature is summarised in Table 3. The beam intensity $\left(E_{\text {in }}\right)$ range (1.0-2.0 keV) used corresponds to a mean positron implantation depth of 40-200 $\mathrm{nm}$ for a material density of $1.0 \mathrm{~g} / \mathrm{cm}^{3}$. The reported free-volume hole-radius for SWRO, LPRO and NF membranes are in the range of $0.24-0.26,0.20-0.29$, and $0.26-0.31 \mathrm{~nm}$, respectively (Table 3). There is thus only a small variation in free-volume hole-radius among the three different membrane categories (i.e., SWRO, LPRO and NF), while the separation of neutral solutes (i.e., boron and NDMA) apparently increases in the order of NF, LPRO and SWRO (Table 1). The overall trend reported suggests that membrane classification (i.e., NF, LPRO and SWRO) is not necessarily based on the free-volume hole-radius. Discussions about the importance of free-volume hole-radius on solute rejection are provided in Section 4. It is 
active skin layer. For example, m-phenylenediamine and trimesoylchloride, which are

398 traditionally used for the interfacial polymerisation of the active skin layer [72], are 399 approximately both $0.35 \mathrm{~nm}$ in width and 0.9 and $1.5 \mathrm{~nm}$ in length, respectively. These small 400 monomers allow the construction of subnanometre-scale polymer network with free-volume 401 holes,

402 Table 3: Free-volume hole-radius of commercial NF/RO membranes analysed by PALS.

\begin{tabular}{llllllll}
\hline Type & Membrane & Manufacturer & Material $^{\mathrm{a}}$ & $\begin{array}{l}E_{\text {in }} \\
{[\mathrm{keV}]}\end{array}$ & $\begin{array}{l}\text { o-Ps } \\
\text { lifetime } \\
{[\mathrm{ns}]}\end{array}$ & $\begin{array}{l}\text { Hole } \\
\text { radius } \\
{[\mathrm{nm}]}\end{array}$ & Ref. \\
\hline \multirow{2}{*}{ SWRO } & SWC5 & Hydranautics/Nitto & PA & 1.0 & 1.75 & 0.259 & {$[20]$} \\
& SW30 & Dow/Filmtec & PA & - & 1.56 & 0.240 & {$[24]$} \\
\hline \multirow{6}{*}{ LPRO } & ESPAB & Hydranautics/Nitto & PA & 1.0 & 2.07 & 0.289 & {$[20]$} \\
& ESPA2 & Hydranautics/Nitto & PA & 1.0 & 2.07 & 0.289 & {$[20]$} \\
& LF10 & Nitto & PA & 2.0 & 1.27 & 0.203 & {$[22]$} \\
& FT30 & Dow/Filmtec & PA & - & 1.37 & 0.217 & {$[23]$} \\
& TFC-HR & Hydranautics/Nitto & PA & 1.0 & 1.83 & 0.267 & {$[69]$} \\
& KG & GE & PA & 1.0 & 1.83 & 0.267 & {$[69]$} \\
& AK & GE & PA & 1.0 & 1.48 & 0.231 & {$[70]$} \\
& NTR729HF & Nitto & PA & 1.0 & 1.57 & 0.241 & {$[70]$} \\
\hline \multirow{5}{*}{ NF } & NTR7250 & Nitto & SPS & 2.0 & 1.79 & 0.265 & {$[22]$} \\
& ESNA-K1 & Hydranautics/Nitto & PPS & 2.0 & 1.85 & 0.271 & {$[22]$} \\
& ESNA-K1 & Hydranautics/Nitto & PA & 2.0 & 1.93 & 0.279 & {$[64]$} \\
& DK & GE & PA & 1.0 & 2.30 & 0.312 & {$[65]$} \\
\hline
\end{tabular}

403

404

405

406

407

408

409

410

411

412

413

414

415

416

${ }^{a}$ PA: Polyamide; SPS: Sulphonated Polyether-Sulphone; n.a.: not available.

PALS using a slow positron beam allows the depth profile of free-volume hole-radii to be evaluated. An example using a LPRO membrane (LF10, NittoDenko) is shown in Figure 9a [22]. The minimum positron lifetime (i.e., $1.26 \mathrm{~ns}$ ) - equivalent to the minimum mean freevolume hole-radius of $0.203 \mathrm{~nm}$ - was obtained with an incident energy $\left(E_{\text {in }}\right)$ of $0.8-2.2 \mathrm{keV}$ corresponding to an average implantation depth of about 40-150 nm (Figure 9a). This indicates that the active skin layer has a uniform size distribution of free-volume hole-radius across its thickness. As $E_{\text {in }}$ further increases from $3 \mathrm{keV}$, more positrons are likely to be injected in a deeper location (e.g., >150 nm in depth) where the interface between the active skin layer and the supporting layer is found. The increased free-volume hole-size as a result of increasing $E_{\text {in }}$ (i.e., 0.21-0.24 nm at 3.0-5.0 keV) (Figure 9a) may indicate the measurement of free-volume hole-radius in the matrix of the supporting layer. Overall, the results here indicate that the thickness of the active skin layer is approximately $150 \mathrm{~nm}$, which is comparable to values reported from high resolution TEM analysis [29]. 

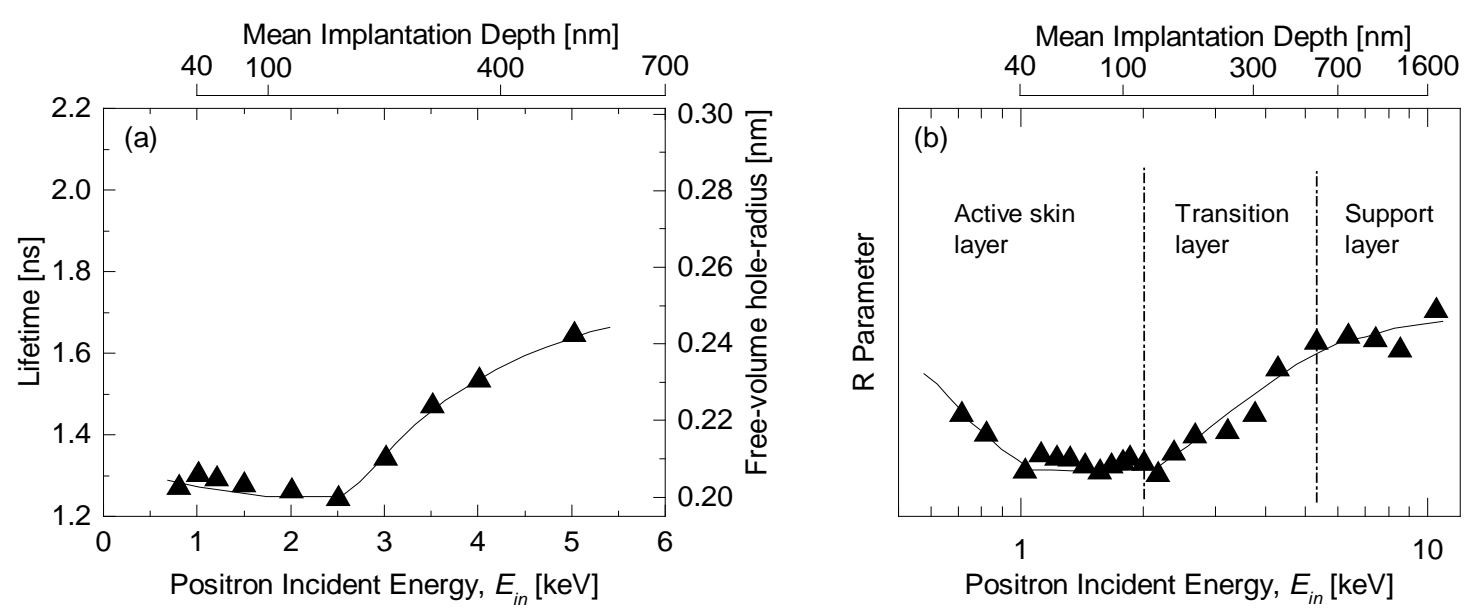

417

Figure 9: Variation in the (a) $o$-Ps lifetime and corresponding free-volume hole-radius and (b) $\mathrm{R}$ parameter as a function of positron incident energy for a LPRO membrane (LF10/Hydranautics) (Reproduced with permission from Ref. [22]. Copyright 2011 ACS Publications).

\subsubsection{Thickness of the active skin layer}

Thickness of the active skin layer and the multiple-layer structure can be estimated from changes in positron annihilation parameters (e.g., positron/o-Ps lifetime and their intensities), and/or the $3-\gamma / 2-\gamma$ ratio (also called the $\mathrm{R}$ parameter). The $\mathrm{R}$ parameter, which can be determined as a function of $E_{i n}$, represents the relative amount of 3- $\gamma$ annihilation that occurs in large (submicron-scale) pores or voids. The $\mathrm{R}$ parameter generally increases with the population of the large holes [62]. Typically, high $\mathrm{R}$ values can be identified at the surface and supporting layers of TFC membranes [73]. For example, $\mathrm{R}$ can be high at the membrane surface $(0.7 \mathrm{keV})$ where more $o$-Ps can escape from shallow free-volume holes via interconnected holes and self-annihilate by 3- $\gamma$ decay (Figure 9b). With positrons penetrating deeper in the sample by increasing $E_{\text {in }}$ between $0.7-1 \mathrm{keV}$, more $o$-Ps undergo 2- $\gamma$ pick-off annihilation resulting in a decrease in $\mathrm{R}$. In the lowest $\mathrm{R}$ region at $1-2.2 \mathrm{keV}, 2 \gamma$ pick-off annihilation predominantly occurred across the membrane, indicating that free-volume holes with a diameter of $<1 \mathrm{~nm}$ are most identified in the 40-150 nm top layer (Figure 9b). The top layer (<150 nm in depth) can be recognised as the active skin layer. Thereafter (e.g., 2.2-5 $\mathrm{keV}$ ), the $\mathrm{R}$ parameter increased (Figure 9b). This indicates that the layer is intermediate between the dense active skin layer and porous supporting layer, which may be called the transition layer. The high $\mathrm{R}$ parameter in the $5-10 \mathrm{keV} E_{\text {in }}$ range can be interpreted as relatively large pores existing in the supporting layer and considerable fraction of $o$-Ps 
441

442

443

444

445

446

447

448

449

450

451

452

453

454

455

456

457

458

459

annihilated there. The results suggest that $\mathrm{R}$ parameter can be a useful indicator to estimate the change of phases (i.e., active skin layer and supporting layer), thus enabling estimating of the thickness of the active skin layer.

\section{Effect of membrane properties on solute rejection}

\subsection{Free-volume hole-radius}

The free-volume hole-size of RO membranes can be the single most important factor governing the separation of small and neutral solutes including boric acid. Thus, rejection of a given solute is expected to vary in response to changes in free-volume hole-size. Indeed, Fujioka et al., [20] showed that the free-volume hole-radius of a SWRO membrane $(0.26 \mathrm{~nm})$ was smaller than that of LPRO membranes $(0.29 \mathrm{~nm})$. Correspondingly, boron rejection by SWRO membranes (81\%) was higher than that by LPRO membranes (36-59\%). Henmi et al., [21] evaluated boron rejection using similar types of SWRO membranes and reported that the rejection of boron decreased with increasing free-volume hole-radius (Figure 10). Several other studies have also revealed a strong correlation between free-volume hole-size and rejection of several other neutral solutes [22, 70]. For example, Chen et al., [22] reported that the rejection of four neutral solutes (urea, ethylene, 1-propanol, and 2-propanol) correlated well with the molecular volume of solutes $\left(V_{m}\right)$ and the volume of sphere-shaped free-volume holes $\left(V_{f}\right)$ in the membrane (Figure 11). The results indicate that free-volume holes play an important role in determining the degree of rejection of neutral solutes.

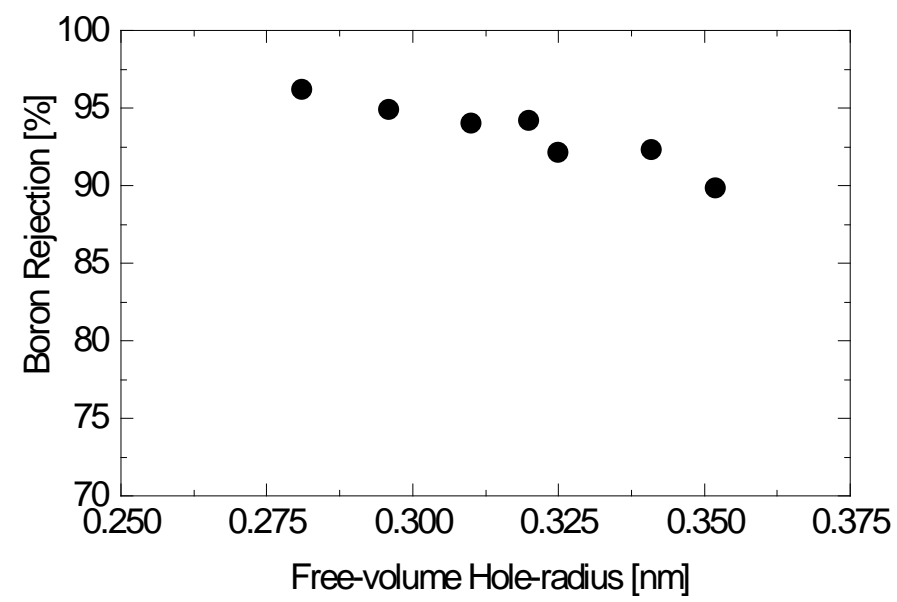

460

461 Figure 10: Boron rejection by SWRO membranes as a function of their free-volume hole462 radius (Reproduced with permission from Ref. [21]. Copyright 2010 IWA Publishing). 


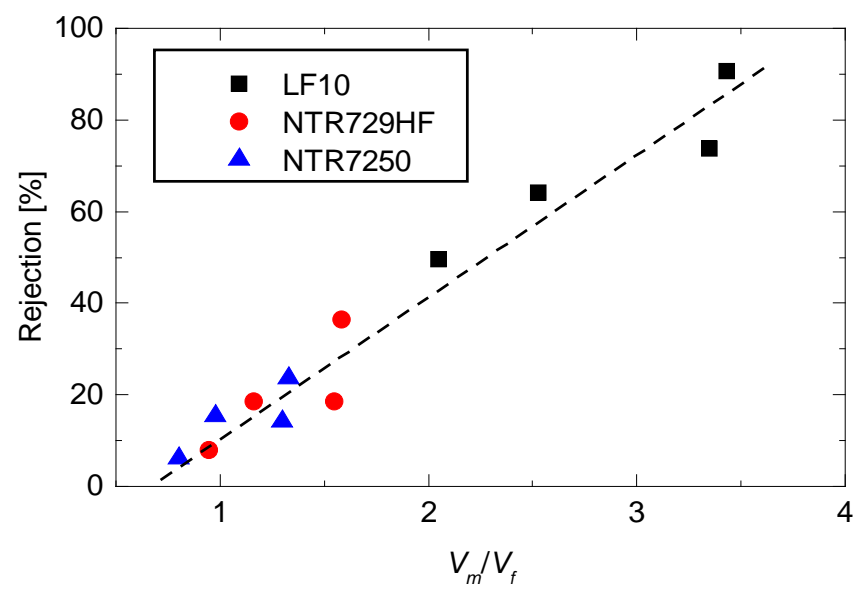

463

464 Figure 11: Correlation between the rejection of the uncharged organic compounds and the 465 ratio of the compound size $\left(V_{m}\right)$ to the free-volume hole size $\left(V_{f}\right)$ for the active skin layer in 466 the RO (LF10) and NF (NTR729HF and NTR7250) membranes (Reproduced with permission 467 from Ref. [22]. Copyright 2011 ACS Publications).

468 In addition to free-volume hole-size, several other membrane properties may influence boron 469 rejection. Sasaki et al., [74] showed that boron rejection by modified SWRO membranes is 470 not clearly correlated with their free-volume hole-radius. Data from other two studies [20, 69] 471 also showed no apparent correlation between free-volume hole-size and boron rejection for 472 LPRO membranes. For example, a large variation in boron rejection (27-69\%) was found 473 between three LPRO membranes with the same free-volume hole-radius (i.e., $0.267 \mathrm{~nm}$ ) [69].

\subsection{Other membrane properties}

475 Other potentially important physicochemical properties of RO membranes for neutral solute 476 rejection include free-volume fraction and thickness, which can vary among RO membranes 477 even with identical mean free-volume hole-radius. No previous studies have evaluated the 478 effect of these properties on neutral solute rejection by RO membranes. This is probably in 479 part due to the technical challenges in their accurate quantification. In general, an increase in 480 free-volume fraction of the active skin layer increases the diffusivity of water and solute, 481 enhancing water permeability and solute permeation. A trade-off between water permeability 482 and solute selectivity has been reported in previous studies [75, 76]. Experimental results 483 from a study by Bernstein et al., [77] (Figure 12) indicate that there is a strong correlation 484 between the permeability of several RO membranes and boron rejection. These results imply 485 that free-volume fraction - an important indicator of permeability - can influence solute 
rejection. The basic solution-diffusion model described in Section 2.2 indicates that solute rejection is dependent on thickness [78]. In addition, an extended solution-diffusion model that has included the concept of free-volume holes shows that solute rejection is determined with these two parameters (i.e., thickness and free-volume fraction) as well as free-volume hole-radius [36]. As a result, solute transport through RO membranes is likely to depend on multiple factors.

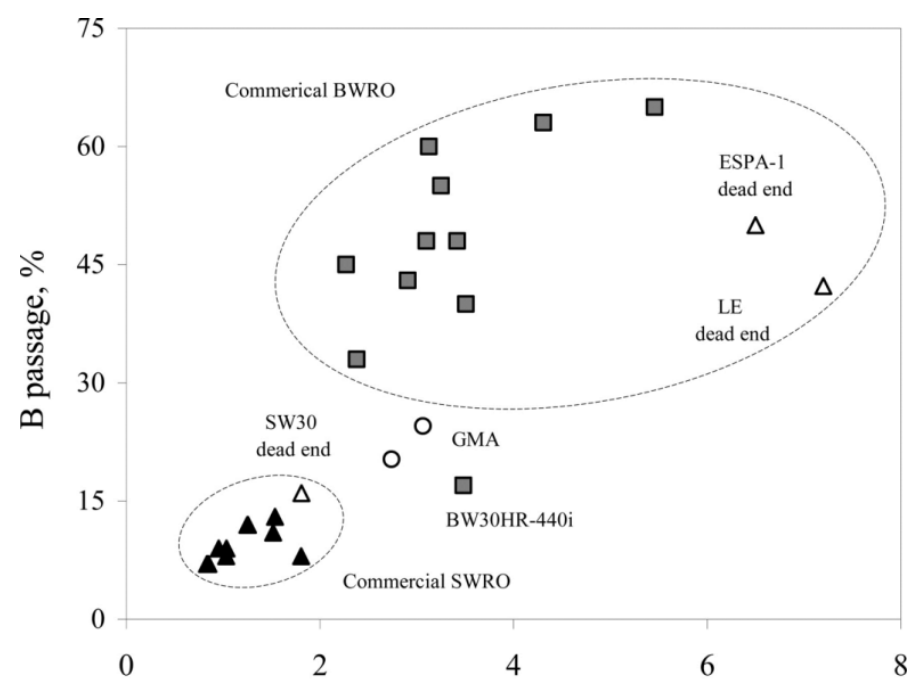

$$
L_{p}\left(\mathrm{~L} \cdot \mathrm{m}^{-2} \cdot \mathrm{h}^{-1} \cdot \mathrm{bar}^{-1}\right)
$$

Figure 12: Boric acid passage and membrane permeability of commercial BWRO (grey squares) and SWRO (black triangles) elements as reported by the manufacturers, Empty triangles show results for commercial membranes tested in dead-end cells and empty circles show the dead-end cell results for LE membranes modified with glycidyl methacrylate $($ GMA) to a different degree (Degree of grafting $=0.67$ and 1.1) (Reproduced with permission from Ref. [77]. Copyright 2011 ACS Journal).

The other property that can potentially influence neutral solute rejection is the real surface area of the top active skin layer. RO filtration systems are generally operated under constant water flux (e.g., $20 \mathrm{~L} / \mathrm{m}^{2} \mathrm{~h}$ for wastewater recycling applications [49]) which is calculated based on their apparent membrane surface area. While a constant water flux can be employed for different RO membranes, their real local water flux can vary depending on the membrane surface conditions. In general, a rougher membrane has a larger surface area (Section 2.1), leading to a higher permeability (Table 4). Membranes with a small surface roughness have a real surface area similar to the apparent surface area. As a result, their real local water flux can be similar to the tested experimental water flux (Table 4). In contrast, membranes with a rougher surface (i.e., a higher surface area) can have a lower real local water flux under the identical apparent water flux. As a result of the decreased local water flux, solute rejection 
also decreases (Table 4) as described in Section 2.2. To evaluate this mechanism, PAS can

511 play an important role in confirming the free-volume hole-radius and thickness of the target 512 membranes.

513 Table 4: Effects of RO membrane active skin layer surface area on solute rejection. The 514 active skin layers in A and B have the same free-volume hole-radius. Apparent surface area 515 and water flux refer to values that can be measured over a large area of sample without taking 516 into account the local (micrometre scale) surface roughness. Real surface area and water flux 517 refer to values calculated at micrometre scale level taking into account the local surface 518 roughness.

\begin{tabular}{|c|c|c|}
\hline Case & A (Low roughness) & B (High roughness) \\
\hline Schematic cross-sectional imag & $\downarrow$ & $J_{B(\text { local })}$ \\
\hline $\begin{array}{l}\text { Properties } \\
\text { a. Apparent surface area } \\
\text { b. Real local surface area } \\
\text { c. Permeability }\end{array}$ & $\begin{array}{c}S_{A} \\
S_{A}(\text { local }) \\
L_{A} \\
\end{array}$ & $\begin{aligned} S_{B} & =S_{A} \\
S_{B(\text { local })} & >S_{A \text { (local) }} \\
L_{B} & >L_{A}\end{aligned}$ \\
\hline $\begin{array}{l}\text { Conditions } \\
\begin{array}{l}\text { a. Apparent water flux } \\
\text { b. Real local water flux } \\
\text { c. Effective pressure } \\
\text { d. Rejection }\end{array}\end{array}$ & $\begin{array}{c}J_{A} \\
J_{A}(\text { local }) \approx J_{A} \\
\Delta P_{A} \\
R_{A}\end{array}$ & $\begin{aligned} J_{B} & =J_{A} \\
J_{B(\text { local) }} & <J_{A} \text { (local) } \\
\Delta P_{B} & <\Delta P_{A} \\
R_{B} & <R_{A}\end{aligned}$ \\
\hline
\end{tabular}

\section{Future research roadmap}

\subsection{Current challenges}

521 State-of-the-art analytical techniques (e.g., PAS, SEM, TEM, and AFM) have allowed RO 522 membrane properties to be comprehensively evaluated as described earlier. Using 523 experimentally evaluated separation performance (e.g., solute rejection and permeability), 524 previous studies [20-22, 70] revealed that free-volume hole-radius in the active skin layer is a 525 key property governing the rejection of small and neutral solutes. Nevertheless, these 526 rejections are not solely dependent on free-volume hole-radius, and there may still be 527 uncertainties with respect to the impact of several other membrane properties. These include 528 free-volume hole-shape, hole-size distribution, and free-volume fraction. While the 529 contribution of these properties to the rejection of uncharged solutes remains unclear, the 
quantification of these membrane properties can greatly assist in furthering our understanding of solute-membrane interaction during RO filtration.

Firstly, free-volume hole-shape can play an important role in the rejection of solutes. Kiso et al., [79] investigated the effects of compound shape on their rejection and reported that the shape of compounds is an important parameter governing their rejections. Thus, a large variation in separation performance is expected among RO membranes with identical freevolume hole-radii but with different shapes. In addition, local segmental dynamics of the polymer chain surrounding a free-volume hole in water, which cannot be evaluated by PAS, but is of great interest. The impact of the local segmental dynamics on the shape and size of free-volume holes, in particular at a high temperature, may be significant. It is noteworthy that free-volume holes analysed using PALS are assumed to be spherical and their shapes cannot be determined by PALS; thus, another analytical technique needs to be developed to clarify the impact of hole geometry on the measurements.

The size distribution of free-volume holes is another potential factor. Given that free-volume hole-size is one of the most important factors, quantification of the hole-size distribution rather than the mean value is required. In typical PALS, free-volume hole-radius is determined as the mean value as described in Section 3.1. The distribution of o-Ps lifetime and corresponding free-volume hole-radius can be estimated by processing the PALS spectrum with inverse Laplace transformation [21, 64, 65, 80]. The lifetime distribution analytical software includes MELT and CONTIN [65, 73, 81]. In some cases, positron annihilation lifetime can be analysed with 4 component lifetimes. For example, the large holes named as nanocavities have been evaluated by using $\tau_{4}$ (>30 ns), resulting in freevolume hole-radii of 1.6-4.6 nm [82]. Kim et al., [23] divided annihilation lifetime (1-5 ns) into two regions - a shorter lifetime $\left(\tau_{3}\right)$ and a longer lifetime $\left(\tau_{4}\right)$ - which in the study corresponded to small ( $r=0.21-0.24 \mathrm{~nm}$ ) and large $(r=0.35-0.45 \mathrm{~nm})$ free-volume holes, respectively. Despite the difficulty in understanding the complete annihilation process of all of positrons through $o$-Ps formation in a sample, it is necessary to reconcile the difference between the actual properties (i.e., hole-shape and hole-size distribution) and the underlying assumption of current PALS techniques (i.e., spherical shape and uniform size). 
559

560

561

562

563

564

565

566

567

568

569

570

571

572

573

574

575

576

577

578

579

580

581

582

583

584

585

586

587

In addition, the free-volume fraction of the active skin layer could also be key factors that influence solute rejection. PAS techniques available to date are not able to quantify the freevolume fraction. This suggests that analytical techniques other than PAS may be required to quantify the free-volume fraction of the active skin layer. Additionally, hole-connectivity is of great interest for understanding solute transport, given that the difference in solute transport phenomenon between the representative two models (i.e., solution-diffusion and pore-flow models) is essentially the permanency of free-volume holes [31]. Some free-volume holes may be independently present as closed holes which clearly are not involved in solute separation.

Another challenge is associated with sample condition. Almost all previous PAS studies using slow positron methods have been performed under vacuum. Membrane sample preparation with drying may cause physical damage to the active skin layer. More importantly, considering RO membranes for water treatment applications are utilised in water under high pressure conditions, free-volume hole-size obtained through the current PALS may be different from actual free-volume hole-size within TFC membranes during filtration. For example, a previous study using RI-based PALS reported that the free-volume hole-radius of SWRO (SW30, Dow/Filmtec) membranes can increase by approximately $0.02 \mathrm{~nm}$ by increasing relative humidity from 0 to $100 \%$ due possibly to hole swelling effects [24]. Swelling may expand the polymer network, hence, influencing the membrane permeability and selectivity $[66,83]$. Although PALS analysis with a slow positron beam under water may be impossible, the impact can be partly clarified by utilising a pulsed beam PALS which is designed to analyse membranes under atmospheric conditions with high humidity [84]. A recent development in PALS allows thin films to be successfully analysed under a range of humidity [85]. There are only a few studies to date where polyamide-based TFC membranes were analysed in a wet state using a slow positron beam [62, 66]. They developed a method that membrane samples are maintained under wet conditions with multiple additional layers placed on the membrane in sealable membrane sample folder. The effect of using a membrane in a wet state in the study [62] was consistent with the previous study where relative humidity was adjusted [24]; that is, free-volume hole enlarges with water content by hole swelling. 
589 As described in Section 5.1, solute rejection by RO membranes can be governed by not only

590 the free-volume hole-radius but also other factors such as hole-shape, hole-size distribution, 591 and free-volume fraction of the active skin layer that may not be measured by PALS. 592 Molecular dynamics (MD) simulation has significant potential to fill the gap and may achieve 593 a breakthrough in understanding the mechanisms of solute rejection. MD simulation has 594 increasingly used to predict solute and water transport through RO membranes at the 595 molecular level [86, 87]. MD simulations, which are based on computational models of 596 597 molecular systems, are capable of describing the solution- and solute-diffusion through membrane polymer chains.

598 A three-dimensional representation of the active skin layer for MD simulation using 599 physicochemical properties (e.g., material compositions, charge density of functional groups, 600 and cross-linking degree) can be constructed. By optimising the polymer chain energy, the 601 three-dimensional representation can then provide further insight about free-volume shape, 602 free-volume fraction, and connectivity of free-volume, which cannot be currently determined 603 by PAS including PALS. The change of molecular structure in pure water as well as in saline 604 water that could occur due to the local segmental dynamics of the polymer chain may also be 605 simulated.

606 An example of MD simulation of the transport of $\mathrm{Na}^{+}, \mathrm{Cl}^{-}$, and water in a polyamide layer is 607 shown in Figure 13 [13]. The diffusivity of water and target compounds in the membrane can 608 be quantified through the MD simulation. As summarised in Table 5, the calculated $\mathrm{Na}^{+}$ 609 diffusivity $\left(D_{\mathrm{Na}}{ }^{+}\right)$in the polyamide is much smaller than that for the calculated water 610 diffusivity ( $D_{\text {water }}$ ) leading to a very large selectivity $\left(D_{\text {water }} / D_{\mathrm{Na}}{ }^{+}\right)$, an order of magnitude 611 greater than for an aqueous $\mathrm{NaCl}$ solution. Because hydrated $\mathrm{Na}^{+}$is larger than water 612 molecule in size, the number of free-volume holes in the molecular model that hydrated $\mathrm{Na}^{+}$ 613 can occupy was far less than that of water molecule. In fact, the mean radius of free-volume 614 holes determined by PALS ( $r=0.24-0.27 \mathrm{~nm}$ ) was smaller than the first hydration shell size 615 of $\mathrm{Na}^{+}$, which is approximately $0.35 \mathrm{~nm}$ [13]. It was postulated that the size of the solute $616\left(\mathrm{Na}^{+}\right)$being larger than most of free-volume holes contributed to the large selectivity $617\left(D_{\text {water }} / D_{\mathrm{Na}}{ }^{+}\right)$in the membrane [13]. Similarly, the impact of free-volume holes on neutral 
solute rejection can also be evaluated by calculating the diffusion coefficients of the solute in

619 the membrane and identifying free-volume holes in the molecular model that are available for 620 the solute to diffuse through. Despite the progressive development and the versatility of MD 621 simulation, it is still necessary to cross-check free-volume hole-size determined by PALS 622 with that calculated by the model. The molecular model used for MD simulation is typically 623 developed by three dimensionally interconnecting a certain length of polymer chains; thus, 624 ensuring the modelled structure represents realistically the molecular structure. In fact, several 625 previous studies $[13,19,66,88]$ have attempted to simulate $\mathrm{NaCl}$ permeation through TFC 626 membranes using MD simulations and PAS data. To the best of our knowledge, no studies 627 have simulated the transport of small and neutral solutes (e.g., boric acid) through RO 628 membranes.

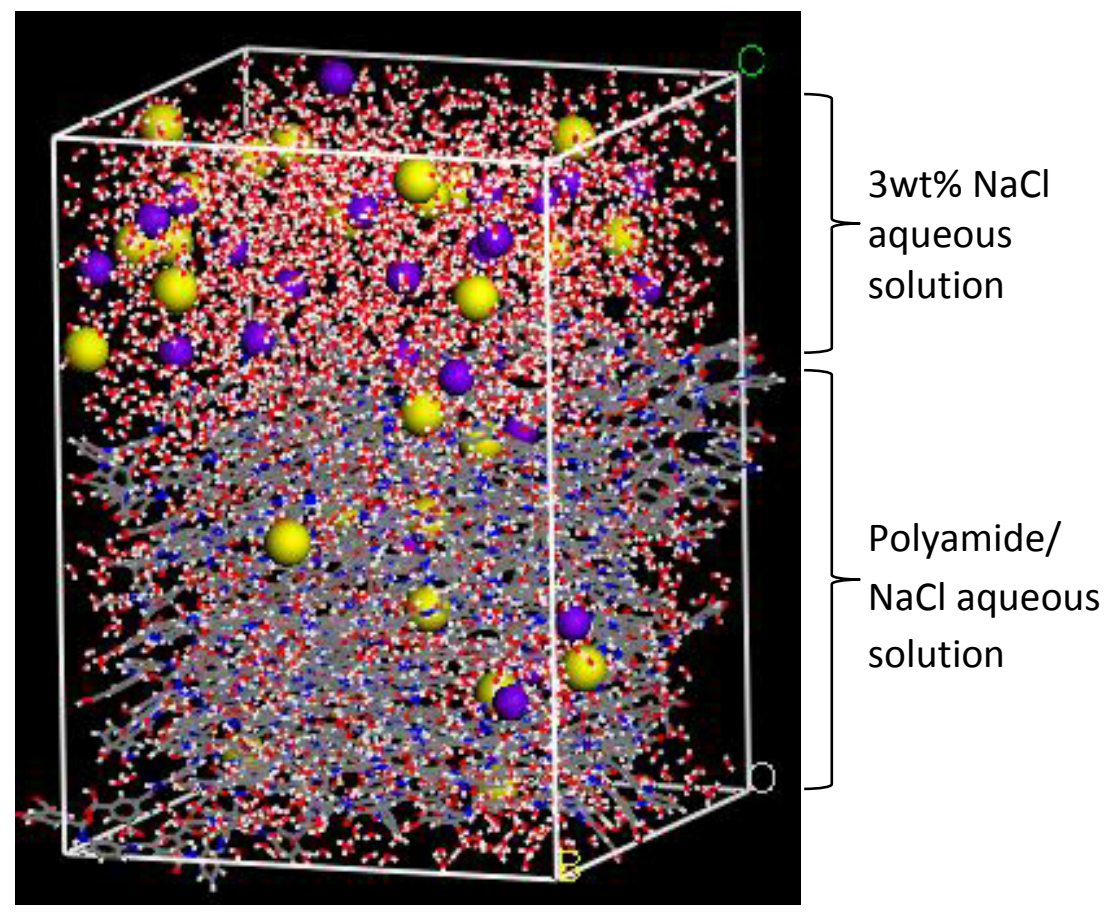

630 Figure 13: Schematics of typical molecular model used for MD simulations. Yellow sphere: $631 \mathrm{Na}^{+}$, Blue sphere: $\mathrm{Cl}^{-}$, Small molecule consisting of red and white lines: Water (Reproduced 632 with permission from Ref. [13]. Copyright IOP Publishing Ltd).

633 Table 5: Diffusion coefficient $\left(\times 10^{10} \mathrm{~m}^{2} / \mathrm{s}\right)$ of water and $\mathrm{Na}^{+}$at $25{ }^{\circ} \mathrm{C}$ that is calculated by 634 MD simulation using the model described in Figure 14 (Reproduced with permission from 635 Ref. [13]. Copyright IOP Publishing Ltd).

\begin{tabular}{lccc}
\hline Material & $D_{\text {water }}$ & $D_{\mathrm{Na}}{ }^{+}$ & $D_{\text {water }} / D_{\mathrm{Na}}{ }^{+}$ \\
\hline NaCl aqueous solution & 26.7 & 10.2 & 2.61 \\
Polyamide & 3.86 & 0.0181 & 213 \\
\hline
\end{tabular}




\section{Conclusions}

637 Further improvements of the RO membrane require a comprehensive understanding of 638 interactions between solute and membrane at near molecular level. Positron annihilation 639 spectroscopy (PAS) using a slow positron beam revealed that RO membranes have a very thin 640 active skin layer with sub-nanometre-sized free-volume holes. Until recently the difficulty in 641 analysing the internal membrane structure has been a major obstacle in elucidating RO 642 membrane transport mechanisms. PAS using a slow positron beam is a powerful tool to 643 investigate the subnanometre-scale inner structure of the active skin layer. Positron 644 annihilation lifetime spectroscopy (PALS) data corroborated in this review showed that 645 commercially available RO membranes have a mean free-volume hole-radius of 0.20-0.29 nm 646 in the active skin layer with the thickness of approximately $100 \mathrm{~nm}$. PALS experimental 647 results clearly show that free-volume hole-size can be the most important parameter 648 determining the rejection of boron which is neutral at environmental $\mathrm{pH}$. The literature data 649 also suggests that, in addition to the free-volume hole-size, the free-volume fraction of the 650 active skin layer may also have an important role in solute rejection. This review article also 651 proposes that another membrane property (i.e., thickness) is a factor influencing solute 652 transport. Major limitations to further understand the solute transport lies in the measurement 653 of free-volume fraction, free-volume hole-shape and hole-size distribution. A better 654 understanding of membrane transport is possible through MD simulation in combination with 655 free-volume hole-size measured by PALS.

\section{References}

657 [1] S. Loeb, S. Sourirajan, Sea Water Demineralization by Means of an Osmotic Membrane, in: Saline Water Conversion II, American Chemical Society, 1963, pp. 117-132.

660 [2] J.E. Cadotte, L.T. Rozelle, In-situ formed condensation polymers for reverse osmosis

661

662

663

664

665 membranes, OSW PB-Report, No 927.

[3] K.P. Lee, T.C. Arnot, D. Mattia, A review of reverse osmosis membrane materials for desalination-Development to date and future potential, J. Membr. Sci., 370 (2011) 122.

[4] M.A. Shannon, P.W. Bohn, M. Elimelech, J.G. Georgiadis, B.J. Marinas, A.M. Mayes, Science and technology for water purification in the coming decades, Nature, 452 (2008) 301-310.

[5] M. Elimelech, The global challenge for adequate and safe water, J. Water Supply: Res. Technol. Aqua, 55 (2006) 3-10. 
[6] B. Van der Bruggen, C. Vandecasteele, T. Van Gestel, W. Doyen, R. Leysen, A review of pressure-driven membrane processes in wastewater treatment and drinking water production, Environ. Prog., 22 (2003) 46-56.

[7] G. Daufin, J.P. Escudier, H. Carrère, S. Bérot, L. Fillaudeau, M. Decloux, Recent and Emerging Applications of Membrane Processes in the Food and Dairy Industry, Food Bioprod. Process., 79 (2001) 89-102.

675

[8] M. Kurihara, M. Hanakawa, Mega-ton Water System: Japanese national research and development project on seawater desalination and wastewater reclamation, Desalination, 308 (2013) 131-137.

[9] USEPA, Integrated Risk Information System (IRIS), http://www.epa.gov/iris/ (1993).

[10] M.H. Plumlee, M. López-Mesas, A. Heidlberger, K.P. Ishida, M. Reinhard, Nnitrosodimethylamine (NDMA) removal by reverse osmosis and UV treatment and analysis via LC-MS/MS, Water Res., 42 (2008) 347-355.

[11] M.J. Farré, K. Döderer, L. Hearn, Y. Poussade, J. Keller, W. Gernjak, Understanding the operational parameters affecting NDMA formation at Advanced Water Treatment Plants, J. Hazard. Mater., 185 (2011) 1575-1581.

[12] K.L. Tu, L.D. Nghiem, A.R. Chivas, Boron removal by reverse osmosis membranes in seawater desalination applications, Sep. Purif. Technol., 75 (2010) 87-101.

[13] A. Shimazu, H. Goto, T. Shintani, M. Hirose, R. Suzuki, Y. Kobayashi, Vacancy profile in reverse osmosis membranes studied by positron annihilation lifetime measurements and molecular dynamics simulations, J. Phys.: Conf. Ser., 443 (2013) 012050.

[14] J.G. Wijmans, R.W. Baker, The solution-diffusion model: a review, J. Membr. Sci., 107 (1995) 1-21.

[15] K. Kosutic, L. Kastelan-Kunst, B. Kunst, Porosity of some commercial reverse osmosis and nanofiltration polyamide thin-film composite membranes, J. Membr. Sci., 168 (2000) 101-108.

[16] Y. Kiso, K. Muroshige, T. Oguchi, M. Hirose, T. Ohara, T. Shintani, Pore radius estimation based on organic solute molecular shape and effects of pressure on pore radius for a reverse osmosis membrane, J. Membr. Sci., 369 (2011) 290-298.

[17] Y.C. Jean, P.E. Mallon, D.M. Schrader, Principles and applications of positron and positronium chemistry, World Scientific, Singapore, 2003.

[18] K.-L. Tung, K.-S. Chang, T.-T. Wu, N.-J. Lin, K.-R. Lee, J.-Y. Lai, Recent advances in the characterization of membrane morphology, Curr. Opin. Chem. Eng., 4 (2014) 121-127.

[19] T. Shintani, A. Shimazu, S. Yahagi, H. Matsuyama, Characterization of methylsubstituted polyamides used for reverse osmosis membranes by positron annihilation lifetime spectroscopy and MD simulation, J. Appl. Polym. Sci., 113 (2009) 1757-1762.

[20] T. Fujioka, N. Oshima, R. Suzuki, S.J. Khan, A. Roux, Y. Poussade, J.E. Drewes, L.D. Nghiem, Rejection of small and uncharged chemicals of emerging concern by reverse osmosis membranes: The role of free volume space within the active skin layer, Sep. Purif. Technol., 116 (2013) 426-432.

[21] M. Henmi, Y. Fusaoka, H. Tomioka, M. Kurihara, High performance RO membranes for desalination and wastewater reclamation and their operation results, Water Sci. Technol., 62 (2010) 2134-2140.

[22] Z. Chen, K. Ito, H. Yanagishita, N. Oshima, R. Suzuki, Y. Kobayashi, Correlation study between free-volume holes and molecular separations of composite membranes 
[23] S.H. Kim, S.-Y. Kwak, T. Suzuki, Positron Annihilation Spectroscopic Evidence to Demonstrate the Flux-Enhancement Mechanism in Morphology-Controlled ThinFilm-Composite (TFC) Membrane, Environ. Sci. Technol., 39 (2005) 1764-1770.

for reverse osmosis processes by means of variable-energy positron annihilation techniques, J. Phys. Chem. C, 115 (2011) 18055-18060.

[24] J. Lee, C.M. Doherty, A.J. Hill, S.E. Kentish, Water vapor sorption and free volume in the aromatic polyamide layer of reverse osmosis membranes, J. Membr. Sci., 425-426 (2013) 217-226.

[25] H. Hagihara, K. Ito, N. Oshima, A. Yabuuchi, H. Suda, H. Yanagishita, Depth profiling of the free-volume holes in cellulose triacetate hollow-fiber membranes for reverse osmosis by means of variable-energy positron annihilation lifetime spectroscopy, Desalination, 344 (2014) 86-89.

[26] R.E. Larson, J.E. Cadotte, R.J. Petersen, The FT-30 seawater reverse osmosis membrane--element test results, Desalination, 38 (1981) 473-483.

[27] T. Uemura, K. Kotera, M. Henmi, H. Tomioka, Membrane technology in seawater desalination: History, recent developments and future prospects, Desalin. Water Treat., 33 (2011) 283-288.

[28] V. Freger, Swelling and morphology of the skin layer of polyamide composite membranes: an atomic force microscopy study, Environ. Sci. Technol., 38 (2004) 3168-3175.

[29] V. Freger, Nanoscale Heterogeneity of Polyamide Membranes Formed by Interfacial Polymerization, Langmuir, 19 (2003) 4791-4797.

[30] C.Y. Tang, Y.-N. Kwon, J.O. Leckie, Probing the nano- and micro-scales of reverse osmosis membranes-A comprehensive characterization of physiochemical properties of uncoated and coated membranes by XPS, TEM, ATR-FTIR, and streaming potential measurements, J. Membr. Sci., 287 (2007) 146-156.

[31] R.W. Baker, Membrane technology and applications, 3rd edition, England, 2012.

[32] C.Y. Tang, Y.-N. Kwon, J.O. Leckie, Effect of membrane chemistry and coating layer on physiochemical properties of thin film composite polyamide RO and NF membranes: I. FTIR and XPS characterization of polyamide and coating layer chemistry, Desalination, 242 (2009) 149-167.

[33] C.Y. Tang, Y.-N. Kwon, J.O. Leckie, Effect of membrane chemistry and coating layer on physiochemical properties of thin film composite polyamide RO and NF membranes: II. Membrane physiochemical properties and their dependence on polyamide and coating layers, Desalination, 242 (2009) 168-182.

[34] D. Li, H. Wang, Recent developments in reverse osmosis desalination membranes, J. Mater. Chem., 20 (2010) 4551-4566.

[35] A.K. Ghosh, B.-H. Jeong, X. Huang, E.M.V. Hoek, Impacts of reaction and curing conditions on polyamide composite reverse osmosis membrane properties, J. Membr. Sci., 311 (2008) 34-45.

[36] J. Wang, D.S. Dlamini, A.K. Mishra, M.T.M. Pendergast, M.C.Y. Wong, B.B. Mamba, V. Freger, A.R.D. Verliefde, E.M.V. Hoek, A critical review of transport through osmotic membranes, J. Membr. Sci., 454 (2014) 516-537.

[37] Y.C. Jean, J.D. Van Horn, W.-S. Hung, K.-R. Lee, Perspective of Positron Annihilation Spectroscopy in Polymers, Macromolecules, 46 (2013) 7133-7145.

[38] H. Yan, X. Miao, J. Xu, G. Pan, Y. Zhang, Y. Shi, M. Guo, Y. Liu, The porous structure of the fully-aromatic polyamide film in reverse osmosis membranes, J. Membr. Sci., 475 (2015) 504-510. 
[39] B. Mi, O. Coronell, B.J. Mariñas, F. Watanabe, D.G. Cahill, I. Petrov, Physicochemical characterization of NF/RO membrane active layers by Rutherford backscattering spectrometry, J. Membr. Sci., 282 (2006) 71-81.

[40] R. Gerard, H. Hachisuka, M. Hirose, New membrane developments expanding the horizon for the application of reverse osmosis technology, Desalination, 119 (1998) 47-55.

[41] T. Matsuura, S. Sourirajan, Reverse osmosis transport through capillary pores under the influence of surface forces, Ind. Eng. Chem. Proc. Des. Dev., 20 (1981) 273-282.

[42] K.S. Spiegler, O. Kedem, Thermodynamics of hyperfiltration (reverse osmosis): criteria for efficient membranes, Desalination, 1 (1966) 311-326.

[43] O. Kedem, A. Katchalsky, Permeability of composite membranes. Part 1.-Electric current, volume flow and flow of solute through membranes, Trans. Faraday Soc., 59 (1963) 1918-1930.

[44] T. Okada, T. Matsuura, A new transport model for pervaporation, J. Membr. Sci., 59 (1991) 133-149.

[45] H.K. Lonsdale, U. Merten, R.L. Riley, Transport properties of cellulose acetate osmotic membranes, J. Appl. Polym. Sci., 9 (1965) 1341-1362.

[46] M. Soltanieh, W.N. Gill, Review of reverse osmosis membranes and transport models, Chem. Eng. Commun., 12 (1981) 279-363.

[47] G.M. Geise, D.R. Paul, B.D. Freeman, Fundamental water and salt transport properties of polymeric materials, Prog. Polym. Sci., 39 (2014) 1-42.

[48] D.R. Paul, Reformulation of the solution-diffusion theory of reverse osmosis, J. Membr. Sci., 241 (2004) 371-386.

[49] T. Fujioka, S.J. Khan, Y. Poussade, J.E. Drewes, L.D. Nghiem, N-nitrosamine removal by reverse osmosis for indirect potable water reuse - A critical review based on observations from laboratory-, pilot- and full-scale studies, Sep. Purif. Technol., 98 (2012) 503-515.

[50] M.J. Farré, J. Keller, N. Holling, Y. Poussade, W. Gernjak, Occurrence of Nnitrosodimethylamine precursors in wastewater treatment plant effluent and their fate during ultrafiltration-reverse osmosis membrane treatment, Water Sci. Technol., 63 (2011) 605-612.

[51] C. Bellona, J.E. Drewes, P. Xu, G. Amy, Factors affecting the rejection of organic solutes during NF/RO treatment - A literature review, Water Res., 38 (2004) 27952809.

[52] K.L. Tu, T. Fujioka, S.J. Khan, Y. Poussade, A. Roux, J.E. Drewes, A.R. Chivas, L.D. Nghiem, Boron as a surrogate for $\mathrm{N}$-nitrosodimethylamine rejection by reverse osmosis membranes in potable water reuse applications, Environ. Sci. Technol., 47 (2013) 6425-6430.

[53] T. Fujioka, S.J. Khan, J.A. McDonald, A. Roux, Y. Poussade, J.E. Drewes, L.D. Nghiem, N-nitrosamine rejection by nanofiltration and reverse osmosis membranes: The importance of membrane characteristics, Desalination, 316 (2013) 67-75.

[54] T. Fujioka, L.D. Nghiem, S.J. Khan, J.A. McDonald, Y. Poussade, J.E. Drewes, Effects of feed solution characteristics on the rejection of N-nitrosamines by reverse osmosis membranes, J. Membr. Sci., 409-410 (2012) 66-74.

[55] T. Fujioka, S.J. Khan, J.A. McDonald, L.D. Nghiem, Nanofiltration of trace organic chemicals: A comparison between ceramic and polymeric membranes, Sep. Purif. Technol., 136 (2014) 258-264. 
[56] B. Van der Bruggen, A. Verliefde, L. Braeken, E.R. Cornelissen, K. Moons, J.Q.J.C. Verberk, H.J.C. van Dijk, G. Amy, Assessment of a semi-quantitative method for estimation of the rejection of organic compounds in aqueous solution in nanofiltration, J. Chem. Technol. Biotechnol., 81 (2006) 1166-1176.

[57] M. Eldrup, D. Lightbody, J.N. Sherwood, The temperature dependence of positron lifetimes in solid pivalic acid, Chem. Phys., 63 (1981) 51-58.

[58] S.J. Tao, Positronium annihilation in molecular substances, J. Chem. Phys., 56 (1972) 5499-5510.

[59] P. Coleman, Positron beams and their applications, World Scientific, Singapore, 2000.

[60] K. Hirata, Y. Kobayashi, Y. Ujihira, Diffusion coefficients of positronium in amorphous polymers, J. Chem. Soc., Faraday Trans., 92 (1996) 985-988.

[61] R. Suzuki, Y. Kobayashi, T. Mikado, H. Ohgaki, M. Chiwaki, T. Yamazaki, T. Tomimasu, Slow positron pulsing system for variable energy positron lifetime spectroscopy, Jpn. J. Appl. Phys., 30 (1991) 532-534.

[62] W.-S. Hung, M. De Guzman, S.-H. Huang, K.-R. Lee, Y.C. Jean, J.-Y. Lai, Characterizing Free Volumes and Layer Structures in Asymmetric Thin-Film Polymeric Membranes in the Wet Condition Using the Variable Monoenergy Slow Positron Beam, Macromolecules, 43 (2010) 6127-6134.

[63] K. Boussu, J. De Baerdemaeker, C. Dauwe, M. Weber, K.G. Lynn, D. Depla, S. Aldea, I.F.J. Vankelecom, C. Vandecasteele, B. Van der Bruggen, Physico-chemical characterization of nanofiltration membranes, Chem. Phys. Phys. Chem., 8 (2007) 370-379.

[64] K.-L. Tung, Y.-C. Jean, D. Nanda, K.-R. Lee, W.-S. Hung, C.-H. Lo, J.-Y. Lai, Characterization of multilayer nanofiltration membranes using positron annihilation spectroscopy, J. Membr. Sci., 343 (2009) 147-156.

[65] D. Nanda, K.-L. Tung, W.-S. Hung, C.-H. Lo, Y.-C. Jean, K.-R. Lee, C.-C. Hu, J.-Y. Lai, Characterization of fouled nanofiltration membranes using positron annihilation spectroscopy, J. Membr. Sci., 382 (2011) 124-134.

[66] Y.-H. Huang, W.-C. Chao, W.-S. Hung, Q.-F. An, K.-S. Chang, S.-H. Huang, K.-L. Tung, K.-R. Lee, J.-Y. Lai, Investigation of fine-structure of polyamide thin-film composite membrane under swelling effect by positron annihilation lifetime spectroscopy and molecular dynamics simulation, J. Membr. Sci., 417-418 (2012) 201-209.

[67] S.-H. Huang, W.-S. Hung, D.-J. Liaw, H.-A. Tsai, G.J. Jiang, K.-R. Lee, J.-Y. Lai, Positron annihilation study on thin-film composite pervaporation membranes: Correlation between polyamide fine structure and different interfacial polymerization conditions, Polymer, 51 (2010) 1370-1376.

[68] J. Albo, H. Hagiwara, H. Yanagishita, K. Ito, T. Tsuru, Structural Characterization of Thin-Film Polyamide Reverse Osmosis Membranes, Ind. Eng. Chem. Res., 53 (2014) 1442-1451.

[69] T. Fujioka, N. Oshima, R. Suzuki, M. Higgins, W.E. Price, R.K. Henderson, L.D. Nghiem, Effect of heat treatment on fouling resistance and the rejection of small and neutral solutes by reverse osmosis membranes, Water Sci. Technol. Water Supply, Article in Press (2015) DOI: 10.2166/ws.2014.2135.

[70] K. Ito, Z. Chen, W. Zhou, N. Oshima, H. Yanagishita, R. Suzuki, Y. Kobayashi, Subnanoscopic holes in composite membranes for desalination elucidated by energytunable positron annihilation, Jpn. J. Poly. Sci. Technol., 69 (2012) 443-447. 
[71] A. Al-Amoudi, Effect of chemical cleaning agents on virgin nanofiltration membrane as characterized by positron annihilation spectroscopy, Sep. Purif. Technol., 110 (2013) 51-56.

[72] J.-E. Gu, S. Lee, C.M. Stafford, J.S. Lee, W. Choi, B.-Y. Kim, K.-Y. Baek, E.P. Chan, J.Y. Chung, J. Bang, J.-H. Lee, Molecular Layer-by-Layer Assembled Thin-Film Composite Membranes for Water Desalination, Adv. Mater., 25 (2013) 4778-4782.

[73] H. Chen, W.-S. Hung, C.-H. Lo, S.-H. Huang, M.-L. Cheng, G. Liu, K.-R. Lee, J.-Y. Lai, Y.-M. Sun, C.-C. Hu, R. Suzuki, T. Ohdaira, N. Oshima, Y.C. Jean, Free-Volume depth profile of polymeric membranes studied by positron annihilation spectroscopy: Layer structure from interfacial polymerization, Macromolecules, 40 (2007) 75427557.

[74] T. Sasaki, H. Tomioka, K. Nakatsuji, Composite semipermeable membrane, production process thereof, and element, fluid separation equipment and treatment method for boron-containing water using the same, in: U.S. Patent (Ed.) United States Patent, Toray Industries, Inc., USA, 2010.

[75] G.M. Geise, H.B. Park, A.C. Sagle, B.D. Freeman, J.E. McGrath, Water permeability and water/salt selectivity tradeoff in polymers for desalination, J. Membr. Sci., 369 (2011) 130-138.

[76] H. Ju, A.C. Sagle, B.D. Freeman, J.I. Mardel, A.J. Hill, Characterization of sodium chloride and water transport in crosslinked poly(ethylene oxide) hydrogels, J. Membr. Sci., 358 (2010) 131-141.

[77] R. Bernstein, S. Belfer, V. Freger, Toward Improved Boron Removal in RO by Membrane Modification: Feasibility and Challenges, Environ. Sci. Technol., 45 (2011) 3613-3620.

[78] S. Bandini, L. Bruni, 2.04 - Transport Phenomena in Nanofiltration Membranes, in: E. Drioli, L. Giorno (Eds.) Comprehensive Membrane Science and Engineering, Elsevier, Oxford, 2010, pp. 67-89.

[79] Y. Kiso, K. Muroshige, T. Oguchi, T. Yamada, M. Hhirose, T. Ohara, T. Shintani, Effect of molecular shape on rejection of uncharged organic compounds by nanofiltration membranes and on calculated pore radii, J. Membr. Sci., 358 (2010) 101-113.

[80] Y.C. Jean, W.-S. Hung, C.-H. Lo, H. Chen, G. Liu, L. Chakka, M.-L. Cheng, D. Nanda, K.-L. Tung, S.-H. Huang, K.-R. Lee, J.-Y. Lai, Y.-M. Sun, C.-C. Hu, C.-C. Yu, Applications of positron annihilation spectroscopy to polymeric membranes, Desalination, 234 (2008) 89-98.

[81] A. Shukla, L. Hoffmann, A.A. Manuel, M. Peter, Melt 4.0 a program for positron lifetime analysis, Mater. Sci. Forum, 255-257 (1997) 233-237.

[82] Q.-F. An, Y.-L. Ji, W.-S. Hung, K.-R. Lee, C.-J. Gao, AMOC Positron Annihilation Study of Zwitterionic Nanofiltration Membranes: Correlation between Fine Structure and Ultrahigh Permeability, Macromolecules, 46 (2013) 2228-2234.

[83] E.P. Chan, A.P. Young, J.-H. Lee, J.Y. Chung, C.M. Stafford, Swelling of ultrathin crosslinked polyamide water desalination membranes, J. Polym. Sci., Part B: Polym. Phys., 51 (2013) 385-391.

[84] N. Oshima, B.E. O'Rourke, R. Kuroda, R. Suzuki, H. Watanabe, S. Kubota, K. Tenjinbayashi, A. Uedono, N. Hayashizaki, Slow Positron Beam Apparatus for Surface and Subsurface Analysis of Samples in Air, Applied Physics Express, 4 (2011) 066701. 
[85] W. Zhou, Z. Chen, N. Oshima, K. Ito, B.E. O’Rourke, R. Kuroda, R. Suzuki, H. Yanagishita, T. Tsutsui, A. Uedono, N. Hayashizaki, In-situ characterization of freevolume holes in polymer thin films under controlled humidity conditions with an atmospheric positron probe microanalyzer, Appl. Phys. Lett., 101 (2012).

[86] E. Harder, D.E. Walters, Y.D. Bodnar, R.S. Faibish, B.t. Roux, Molecular Dynamics Study of a Polymeric Reverse Osmosis Membrane, J. Phys. Chem. B, 113 (2009) 10177-10182.

913

[87] Z.E. Hughes, J.D. Gale, Molecular dynamics simulations of the interactions of potential foulant molecules and a reverse osmosis membrane, J. Mater. Chem., 22 (2012) 175-184.

[88] K.-S. Chang, Y.-H. Huang, K.-R. Lee, K.-L. Tung, Free volume and polymeric structure analyses of aromatic polyamide membranes: A molecular simulation and experimental study, J. Membr. Sci., 354 (2010) 93-100. 